\title{
A zeolite 13X/magnesium sulfate-water sorption thermal energy storage device for domestic heating
}

\author{
S.Z. Xu ${ }^{\text {a,b }}$, Lemington a, R.Z. Wang a, ${ }^{\text {a }}$, L.W. Wang a, J. Zhu ${ }^{\text {b }}$ \\ ${ }^{a}$ Institute of Refrigeration and Cryogenics, Key Laboratory for Power Machinery and Engineering of \\ M.O.E, Shanghai Jiao Tong University, 800 Dongchuan Road, Shanghai 200240, PR China \\ ${ }^{\mathrm{b}}$ Department of Architecture and Built Environment, University of Nottingham, \\ University Park, Nottingham NG7 2RD, United Kingdom \\ E-mails: zhizhi@sjtu.edu.cn (S.Z.Xu); rzwang@sjtu.edu.cn (R.Z. Wang); lwwang@sjtu.edu.cn (L.W. Wang); \\ jie.zhu@nottingham.ac.uk (J. Zhu). \\ * Corresponding author; E-mail: rzwang@sjtu.edu.cn; Tel./fax: +86 2134206548.
}

\begin{abstract}
A sorption thermal energy storage (TES) device for domestic heating is presented in this article. The TES device adopts the new design scenario with valve-less adsorber and separate reservoir to eliminate the largediameter vacuum valve for vapor flow, which decreases the cost, reduces the vapor flow resistance, and improves the system reliability. The device is charged by the electric heater, which can add much flexibility to the building energy system as well as contribute to the valley filling and peak shaving from demand side management. The newly developed composite sorbent of zeolite $13 \mathrm{X} / \mathrm{MgSO}_{4} / \mathrm{ENG}-\mathrm{TSA}$ (expanded natural graphite treated with sulfuric acid) with the salt mass fraction of $15 \%$ in the zeolite $13 \mathrm{X} / \mathrm{MgSO}_{4}$ mixture is tested and used in the TES device (denoted as XM15/ENG-TSA). Experimental results show that the TES device with XM15/ENG-TSA has the energy storage density of $120.3 \mathrm{kWh} \cdot \mathrm{m}^{-3}$ at $250{ }^{\circ} \mathrm{C}$ charging temperature and $25-90{ }^{\circ} \mathrm{C}$ discharging temperature. The temperature lift is as high as $65-69^{\circ} \mathrm{C}$ with the adsorption and evaporating temperatures of $25^{\circ} \mathrm{C}$. The impregnation of $\mathrm{MgSO}_{4}$ dramatically improves the temperature rising rate during the adsorption heat recovery process, but the specific energy storage capacity of XM15/ENG-TSA is similar to that of zeolite $13 \mathrm{X} / \mathrm{ENG}-\mathrm{TSA}$. The effect of the impregnated $\mathrm{MgSO}_{4}$ suggests that $\mathrm{MgSO}_{4}$ can be used for low-temperature TES to relieve the self-hindrance of the hydration reaction.
\end{abstract}

Keywords: Thermal energy storage; Adsorption; Zeolite 13X; Magnesium sulfate; Composite sorbent. 


\section{Nomenclature}

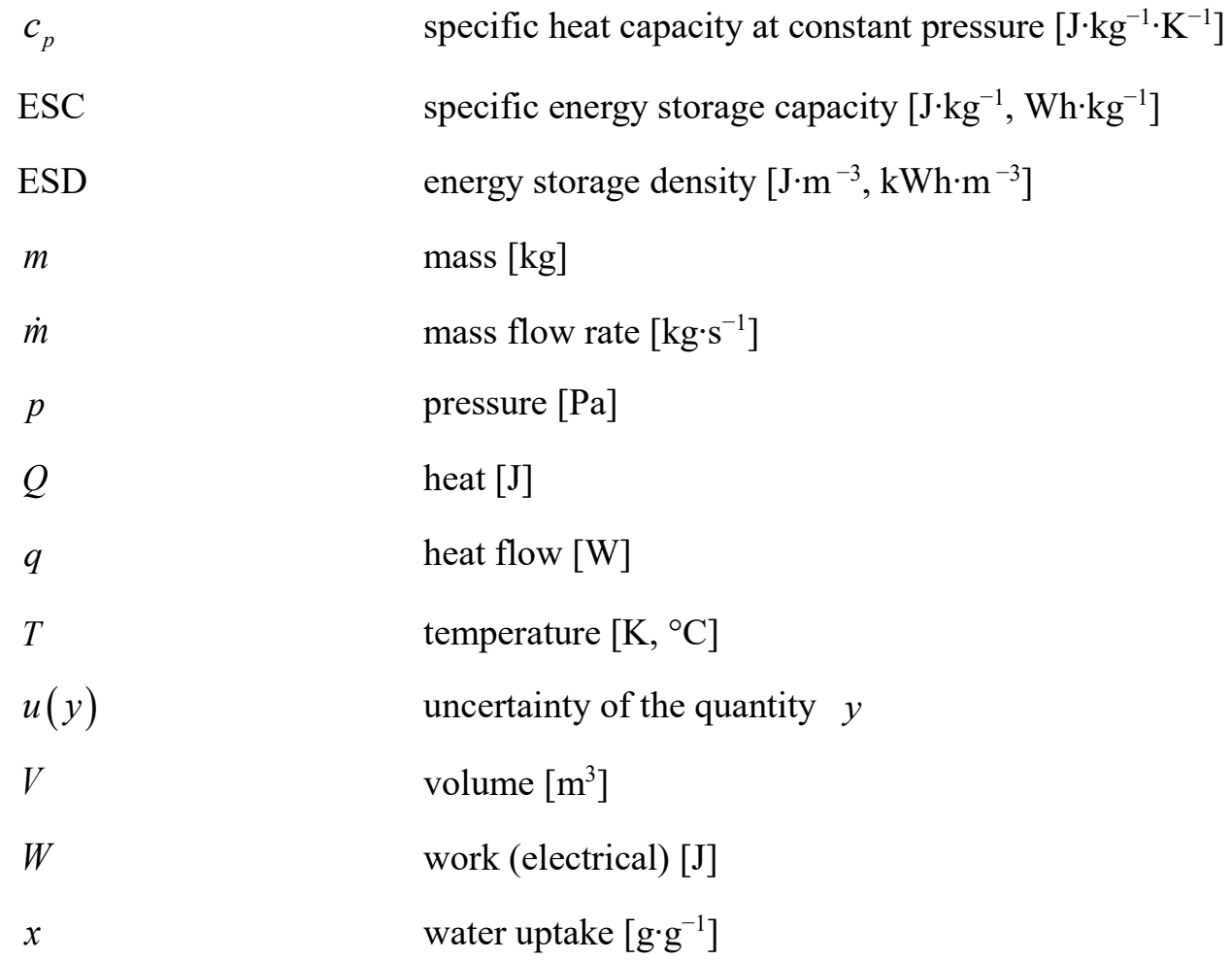

specific heat capacity at constant pressure $\left[\mathrm{J} \cdot \mathrm{kg}^{-1} \cdot \mathrm{K}^{-1}\right]$

specific energy storage capacity $\left[\mathrm{J} \cdot \mathrm{kg}^{-1}, \mathrm{Wh} \cdot \mathrm{kg}^{-1}\right]$

energy storage density $\left[\mathrm{J} \cdot \mathrm{m}^{-3}, \mathrm{kWh} \cdot \mathrm{m}^{-3}\right]$

mass $[\mathrm{kg}]$

mass flow rate $\left[\mathrm{kg} \cdot \mathrm{s}^{-1}\right]$

pressure $[\mathrm{Pa}]$

heat $[\mathrm{J}]$

heat flow [W]

temperature $\left[\mathrm{K},{ }^{\circ} \mathrm{C}\right]$

uncertainty of the quantity $y$

volume $\left[\mathrm{m}^{3}\right]$

work (electrical) [J]

water uptake $\left[\mathrm{g}^{-\mathrm{g}^{-1}}\right]$

\section{Subscripts}

A

a

C

chg

D

dis

E

eh

f

$\max$

maximum error of the quantity $y$

energy efficiency

time $[\mathrm{s}, \mathrm{h}]$

adsorption/sorption, adsorption heat recovery

adsorbent/sorbent

condensing, condensation

charging

desorption, dehydration

discharging

evaporating, evaporation

electric heater

fluid

maximum 


$\begin{array}{ll}\min & \text { minimum } \\ \mathrm{R} & \text { reservoir } \\ \mathrm{S} & \text { sensible heat recovery } \\ \text { sat } & \text { saturation }\end{array}$

Superscripts

normalized

\section{Introduction}

In the recent decades, increasing energy consumption and depletion of fossil fuels have motivated the world to shift attention to sustainable development [1]. Pursuing better utilization of energy [2] and steering to renewable energy [3] have been the two main practical approaches leading to energy conservation and emission reduction. On the one hand, discrepancies between the demand and supply sides of energy lie in many aspects including time, space, and power. On the other hand, some kinds of renewable energy such as solar energy suffer from the defects of intermittence and instability [4]. Energy storage system is one of the solutions to these issues since it is capable of relieving or eliminating the time discrepancy and the instability between energy supply and demand [5]. Compared with mechanical and electrical energy storage, thermal energy storage (TES) enjoys the merits of low cost, suitability for bulk energy storage, and natural combination with solar systems. TES systems implemented in buildings offer a vast range of opportunities and benefits to reduce emissions [6], and they are crucial components of concentrating solar power plants to allow enough dispatchability as well as adapt the electric power production to the demand curve [7].

TES can be divided into three categories according to the form how energy is stored, i.e., sensible, latent, and thermochemical (including sorption and chemical reaction) heat storage [6]. Sensible heat storage has the advantages of low cost and simple system structure; however, the energy storage density is low. For the sensible heat storage with water as the medium, the energy storage density is approximately $200 \mathrm{MJ} \mathrm{m}^{-3}$ for the temperature difference of $50^{\circ} \mathrm{C}$. Latent heat storage uses phase change material (PCM) as the medium, which can store a larger amount of thermal energy with a narrower range of temperature near the phase change temperature of the material compared to sensible heat storage. The energy storage density of PCM is around 300-500 $\mathrm{MJ} \mathrm{m}^{-3}[8]$. Thermochemical heat storage has the highest heat storage density compared to sensible and latent heat storage. Depending on the thermochemical storage medium, the heat storage density is as high as $1000-2000 \mathrm{MJ} \mathrm{m}^{-3}$. Thermochemical materials can store energy at the ambient temperature without self- 
discharging and experience a significant temperature lift during discharging, which is a crucial character for long-term and seasonal TES [8].

Among all the energy-consuming sectors, building is responsible for $35 \%$ of the global final energy consumption. In China, $71 \%$ of the total final energy demand in the residential sub-sector lies in water and space heating [9]. In the United Kingdom, space and water heating accounts for approximately $80 \%$ of the energy consumed in the domestic sector, among which direct gas use delivers $72 \%$, and electricity contributes $22 \%$ to the heat used for space heating [10]. TES and electricity-to-heat are regarded as the useful approaches to improve the flexibility of building energy systems [11]. Electrically driven thermal energy storage (ETES) system is the combination of the two approaches, which can convert electricity to heat and store the thermal energy when there is excess (renewable) electricity or during off-peak hours. The stored thermal energy is discharged during peak time or periods lacking in renewable electricity [12]. From the concept of demand side management, ETES systems can shift the load of the end-use electricity consumption. The capabilities of valley filling and peak shaving of ETES systems can improve the pattern and magnitude of the electricity consumption. Furthermore, by replacing heat production from fossil fuels, ETES systems can reduce emissions and significantly increase the useful share of renewable energy sources [13]. In consequence, ETES systems with thermochemical materials are promising to be implemented in buildings as they can deliver high flexibility by the realization of long-term TES within relatively small system sizes and finally contribute to energy conservation and emission reduction.

Physical adsorption, liquid absorption, and chemical reaction are all grouped into thermochemical heat storage [6]. To fulfill the requirement for space heating and domestic hot water, the discharging temperature of the TES system should be in the range of $21-95^{\circ} \mathrm{C}$ [11], and the hot water temperature for the heat user can be regulated depending on the user demand. Shigeishi et al. [14] investigated the energy storage properties of molecular sieves 4A, 5A, 13X, charcoal, activated alumina, and silica gel. They found that zeolite $13 \mathrm{X}$ is the best adsorbent among these materials. The EU MODSTORE project [15] built a laboratory-scale silica gelwater TES unit which realizes a temperature lift of $15^{\circ} \mathrm{C}$ with the maximum adsorption temperature of $70{ }^{\circ} \mathrm{C}$ charged by the heating source at $88^{\circ} \mathrm{C}$, and the energy storage density is $50 \mathrm{kWh} \cdot \mathrm{m}^{-3}$. Dawoud et al. [16] presented a closed-system zeolite 13X-water TES device charged by hot fluid with the energy efficiency of about $0.43-0.67$ and the energy storage density as high as $91.76 \mathrm{kWh} \cdot \mathrm{m}^{-3}$. The temperature lift of the device is about $30^{\circ} \mathrm{C}$ for the heat storage time of 5 hours. Tatsidjodoung et al. [17] studied an open-system zeolite $13 \mathrm{X}$-water solar heat storage system for buildings. An average temperature lift of $38^{\circ} \mathrm{C}$ is realized with $80 \mathrm{~kg}$ of dry zeolite 13X. Schreiber et al. [18] applied a closed-system zeolite 13X-water TES unit to the cogeneration in industrial batch processes. They found that adsorption TES has the potential to reduce primary 
energy consumption by up to $25 \%$.

It can be concluded that zeolite $13 \mathrm{X}$ is one of the best TES materials for domestic heating, as the maximum adsorption temperature can be higher than $100{ }^{\circ} \mathrm{C}$. Zeolites also can provide higher temperature lifts than silica gel. The typical regeneration temperature of zeolite $13 \mathrm{X}$ is $200-250^{\circ} \mathrm{C}$, which can be easily achieved by an electric heater. Consequently, zeolite $13 \mathrm{X}$ is chosen as the host porous matrix for the ETES system in this article. The performance of zeolite $13 \mathrm{X}$ can be further improved by producing porous matrix composite materials with appropriate chemicals [4]. An alkali and several salts are selected as optional chemicals for the zeolite $13 \mathrm{X}$-based composite sorbents. $\mathrm{NaOH}$-water absorption is reported to be able to realize the $40-70{ }^{\circ} \mathrm{C}$ discharging temperature with the charging temperature of $150{ }^{\circ} \mathrm{C}$ at the energy storage density of $250 \mathrm{kWh} \cdot \mathrm{m}^{-3}$ [19]; however, the high corrosion of $\mathrm{NaOH}$ is a potentially severe issue. The theoretical energy storage density of $\mathrm{MgCl}_{2}$ is about $600 \mathrm{kWh} \cdot \mathrm{m}^{-3}$. An open-system $\mathrm{MgCl}_{2}$-water TES porotype is reported to have the energy storage density of around $140 \mathrm{kWh} \cdot \mathrm{m}^{-3}$ discharging at $50-64{ }^{\circ} \mathrm{C}$ and charging at $130{ }^{\circ} \mathrm{C}[20]$, but high charging temperatures over $138^{\circ} \mathrm{C}$ result in the decomposition reaction of $\mathrm{MgCl}_{2} \cdot 2 \mathrm{H}_{2} \mathrm{O}$ producing $\mathrm{MgOHCl}, \mathrm{HCl}$, and water [21]. The theoretical maximum material energy density of $\mathrm{CaCl}_{2}$-water absorption with $80 \%$ solid crystals is $263 \mathrm{kWh} \cdot \mathrm{m}^{-3}$ [22]. $\mathrm{CaCl}_{2}$ is found to agglomerate and form a gel-like material during hydration, which impedes further water uptake of the salt [23]. Silica gel has been used as the host matrix of $\mathrm{CaCl}_{2}$ to mitigate the issue of agglomeration. The silica gel/ $\mathrm{CaCl}_{2}$ materials are reported to have the energy storage density of $211 \mathrm{kWh} \cdot \mathrm{m}^{-3}$ [24] and the maximum discharging temperature of $63{ }^{\circ} \mathrm{C}$ [25]. $\mathrm{MgSO}_{4} \cdot 7 \mathrm{H}_{2} \mathrm{O}$ has the theoretical energy storage density of $780 \mathrm{kWh} \cdot \mathrm{m}^{-3}$ and can be dehydrated by $150{ }^{\circ} \mathrm{C}$ heating source. The initial experiment of material characterization suggests that the effective energy density is reduced to $420 \mathrm{kWh} \cdot \mathrm{m}^{-3}$ under suitable operating conditions [26].

Zeolite $13 \mathrm{X} / \mathrm{MgSO}_{4}$ is a promising composite TES medium for ETES systems. Hongois et al. [27] suggested $15 \%$ mass fraction of $\mathrm{MgSO}_{4}$ be impregnated in zeolite $13 \mathrm{X}$ pellets. The test results of the $200 \mathrm{~g}$ zeolite $13 \mathrm{X} / \mathrm{MgSO}_{4}$ sample demonstrate the temperature lift of $33{ }^{\circ} \mathrm{C}$ and the energy storage density of $166 \mathrm{kWh} \cdot \mathrm{m}^{-3}$ which is $27 \%$ higher than that of pure zeolite13X. Nonetheless, Mahon et al. [28] reported that $\mathrm{MgSO}_{4}$ impregnated zeolite $13 \mathrm{X}$ does not show the sign of $\mathrm{MgSO}_{4}$ dehydration according to differential scanning calorimetry results, which is contradict with the result presented by Hongois et al. [27]. In view of the different voices, further research should be conducted on this promising long-term TES material. Expanded natural graphite treated with sulfuric acid (ENG-TSA) is added to fill the gap of the pellets in order to enhance heat transfer of the zeolite $13 \mathrm{X} / \mathrm{MgSO}_{4}$ composite sorbent. ENG-TSA is reported to improve the thermal conductivity of the consolidated composite activated carbon to as high as $34.2 \mathrm{~W} \cdot \mathrm{m}^{-1} \cdot \mathrm{K}^{-1}$ [29]. Adding ENGTSA to $\mathrm{SrBr}_{2}$ for TES is also reported to improve the heat transfer performance of the material without affection 
of the water uptake [30].

The target of this study is to provide a more feasible TES scheme for domestic heating. This article presents a novel design scenario for sorption TES with valve-less adsorber and separate reservoir. The new design scenario eliminates the large-diameter vacuum valve between the adsorber and the condenser/evaporator for vapor flow in the previous studies, which decreases the cost, reduces the vapor flow resistance, and improves the system reliability. The previous studies mainly use hot fluid to charge the TES system, but hot fluid or waste heat at the temperature higher than $200{ }^{\circ} \mathrm{C}$ is usually unavailable in real building energy systems. The TES device presented in this article is charged by the electric heater and can utilize excess electricity in the grid or from the renewable energy sources. The electrically driven TES can add much flexibility to the building energy system as well as contribute to the valley filling and peak shaving from demand side management. The experimental results show that the presented sorption TES device with the newly-developed zeolite $13 \mathrm{X} / \mathrm{MgSO}_{4} / \mathrm{ENG}$-TSA composite sorbent has an adequate performance and is suitable for domestic heating. The outcomes of this study make the household use of the TES device more achievable.

\section{Materials}

Two kinds of materials were selected as the TES sorbents in this article, i.e., zeolite 13X/ENG-TSA and zeolite $13 \mathrm{X} / \mathrm{MgSO}_{4} / \mathrm{ENG}-\mathrm{TSA}$. The sorption and desorption characterizations of the materials were tested.

\subsection{Material preparation}

Figure 1a shows the preparation steps of zeolite 13X/ENG-TSA. First, zeolite 13X pellets with the diameter of $4 \mathrm{~mm}$ are dried in the oven and cooled down (1). Then the dried zeolite 13X pellets are mixed with ENG-TSA to improve the thermal conductivity (2). After the constituents are mixed evenly (3), the zeolite 13X/ENG-TSA material is filled into the adsorber through a mold (4) and then slightly compressed to the density of about $673 \mathrm{~kg} \cdot \mathrm{m}^{-3}(5)$. At the mass ratio of 1:20 between ENG-TSA and zeolite 13X, ENG-TSA can well occupy the gaps between zeolite pellets after slight compression and will not impede the mass transfer of water vapor.

Figure $1 \mathrm{~b}$ illustrates the preparation procedure of zeolite $13 \mathrm{X} / \mathrm{MgSO}_{4}$ material. First, zeolite $13 \mathrm{X}$ pellets with the diameter of $4 \mathrm{~mm}$ are dried in the oven and cooled down (1). Then the magnesium sulfate aqueous solution is added to dried zeolite $13 \mathrm{X}$ pellets to impregnate $\mathrm{MgSO}_{4}$ into the host matrix of zeolite $13 \mathrm{X}(2)$. The mixture is stirred until the $\mathrm{MgSO}_{4}$ solution is sucked by the zeolite pellets, and the mixture is let stand for 48 hours and occasionally stirred during this period to ensure the uniform content of the salt (3). Afterwards, the 
material is dried again to remove water (4). The mass fraction of $\mathrm{MgSO}_{4}$ is chosen as $15 \%$ as recommended through controlling the amount of $\mathrm{MgSO}_{4}$ solution added [27], [31]. After the zeolite $13 \mathrm{X} / \mathrm{MgSO}_{4}$ material with the salt mass fraction of $15 \%$ (denoted as XM15) is cooled down, it is mixed with ENG-TSA and filled into the adsorber according to the second to the fifth steps in Figure 1a. The sorbent is compressed to the density of $786 \mathrm{~kg} \cdot \mathrm{m}^{-3}$. Zeolite $13 \mathrm{X} / \mathrm{MgSO}_{4} / \mathrm{ENG}-\mathrm{TSA}$ can be made either through adding ENG-TSA to zeolite $13 \mathrm{X} / \mathrm{MgSO}_{4}$ or through impregnating $\mathrm{MgSO}_{4}$ to zeolite $13 \mathrm{X} / \mathrm{ENG}-\mathrm{TSA}$, as ENG-TSA nearly does not absorb water, and most of the aqueous solution added will be sucked by zeolite $13 \mathrm{X}$.

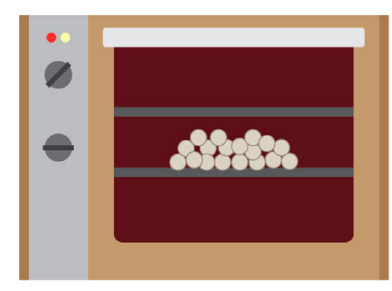

(1)
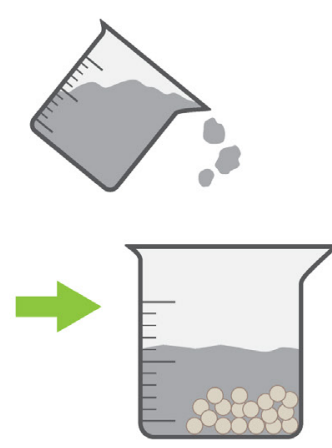

(2)

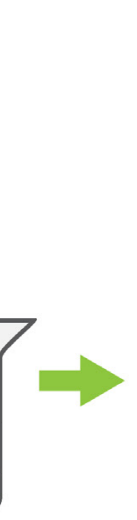

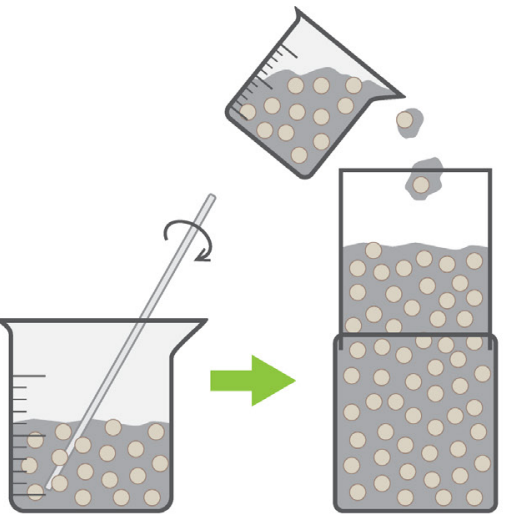

(3)
(4)

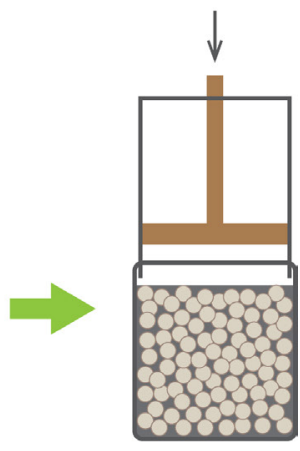

(5)

(a)

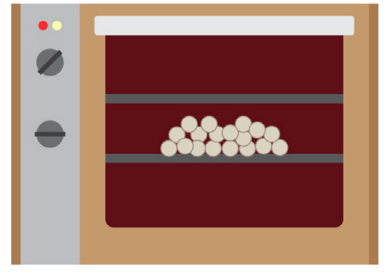

(1)

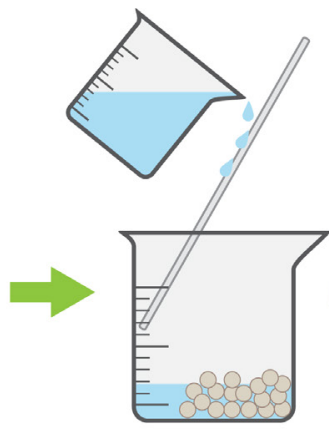

(2)

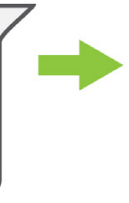

(b)

(b)

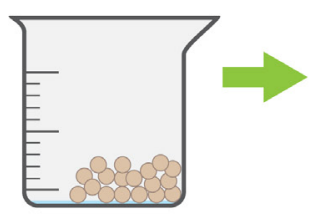

(3)

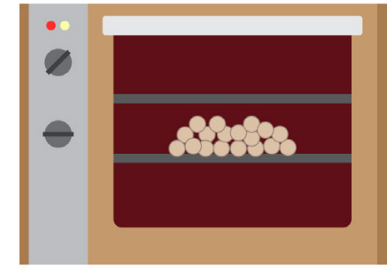

(4)

Figure 1. The preparation procedures of (a) zeolite $13 \mathrm{X} / \mathrm{ENG}-\mathrm{TSA}$ and (b) zeolite $13 \mathrm{X} / \mathrm{MgSO}_{4}$.

\subsection{Material characterizations}

The water uptake kinetic characteristics of zeolite $13 \mathrm{X}$ and XM15 pellets were tested through the measurement of the mass variation with respect to time of the sorbent samples in the constant temperature and humidity chamber. The samples were dried in the oven at $200{ }^{\circ} \mathrm{C}$ before the test. Figure 2 demonstrates the water uptakes of zeolite $13 \mathrm{X}$ and XM15 pellets as functions of time at the saturated temperatures of $25^{\circ} \mathrm{C}$, 
$30{ }^{\circ} \mathrm{C}, 35^{\circ} \mathrm{C}$, and $40{ }^{\circ} \mathrm{C}$, respectively.

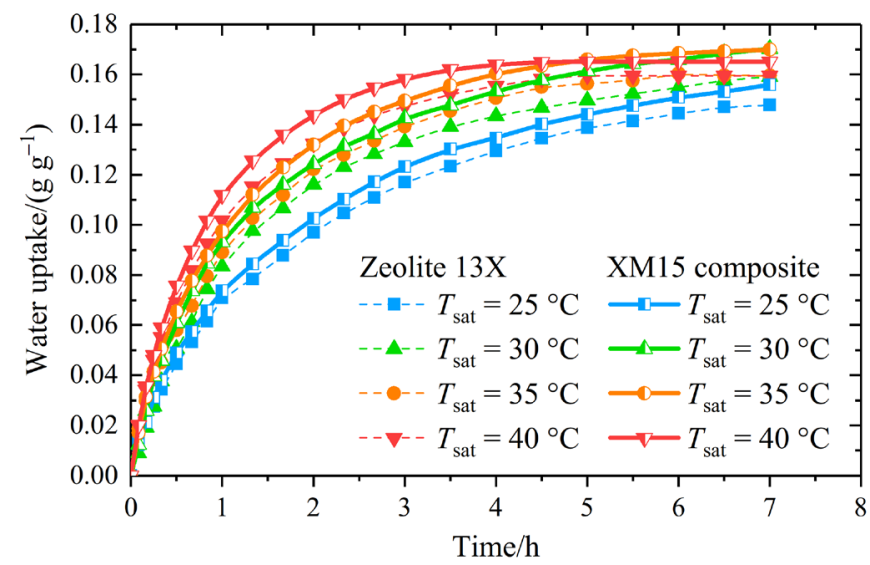

Figure 2. Water uptake kinetic characteristics of zeolite $13 \mathrm{X}$ and XM15 pellets at the saturation temperatures of $25^{\circ} \mathrm{C}$, $30{ }^{\circ} \mathrm{C}, 35^{\circ} \mathrm{C}$, and $40^{\circ} \mathrm{C}$.

As shown in Figure 2, the water uptake kinetic performance of XM15 is always better than that of pure zeolite 13X. XM15 has merits in water uptake rate as well as maximum water uptake over pure zeolite $13 \mathrm{X}$ at every saturated temperature tested. For both materials, the higher saturation temperature results in the higher water uptake rate. For example, at $40{ }^{\circ} \mathrm{C}$ saturation temperature, the water uptake of XM15 reaches $95 \%$ of the maximum after less than 3 hours of sorption, and pure zeolite 13X requires about 3.5 hours to reach $95 \%$ of the maximum water uptake under the same condition; however, at the saturation temperature of $25^{\circ} \mathrm{C}$, both zeolite $13 \mathrm{X}$ and XM15 need about 6.5 hours to reach $95 \%$ of the maximum water uptake. The maximum water uptakes range from $0.148 \mathrm{~g} \cdot \mathrm{g}^{-1}$ to $0.160 \mathrm{~g} \cdot \mathrm{g}^{-1}$ for zeolite $13 \mathrm{X}$ and range from $0.156 \mathrm{~g} \cdot \mathrm{g}^{-1}$ to $0.170 \mathrm{~g} \cdot \mathrm{g}^{-1}$ for XM15 at the given saturation temperatures.

The simultaneous thermal analyzer (Netzsch STA 449 F3) conducted the thermogravimetric analysis and differential scanning calorimetry (TGA/DSC) for zeolite 13X and XM15. The mass loss and the heat flow of the pellet samples as functions of temperature were synchronously measured in the heating and desorption process at the temperature rising rate of $5^{\circ} \mathrm{C} \cdot \mathrm{min}^{-1}$. The samples were fully adsorbed at $30{ }^{\circ} \mathrm{C}$ and $60 \% \mathrm{RH}$ in the constant temperature and humidity chamber before the test. Figure 3 shows the simultaneous thermal analysis (STA) results of zeolite 13X and XM15 pellets.

As illustrated in Figure 3, the water uptake differences of zeolite $13 \mathrm{X}$ and XM15 pellets under $250{ }^{\circ} \mathrm{C}$ desorption temperature are $0.188 \mathrm{~g} \cdot \mathrm{g}^{-1}$ and $0.197 \mathrm{~g} \cdot \mathrm{g}^{-1}$, respectively. The maximum water uptake of XM15 is a bit higher than that of pure zeolite $13 \mathrm{X}$, which is comparable to the result of water uptake kinetic characteristics shown in Figure 2. The maximum heat flow of zeolite 13X pellet in the heating and desorption 
process is $-0.323 \mathrm{~W} \cdot \mathrm{g}^{-1}$ measured at $145.5^{\circ} \mathrm{C}$. XM15 experiences two heat flow peaks during dehydration, the first peak is located at $93.2{ }^{\circ} \mathrm{C}$ with the normalized heat flow of $-0.386 \mathrm{~W} \cdot \mathrm{g}^{-1}$, and the second peak is measured at $147.9^{\circ} \mathrm{C}$ with the normalized heat flow of $-0.368 \mathrm{~W} \cdot \mathrm{g}^{-1}$. The interpretation is that the first peak comes from the impregnated $\mathrm{MgSO}_{4}$, the second peak is originated from zeolite 13X, and the overall heat flow of the sorbent is improved by the impregnated $\mathrm{MgSO}_{4}$. According to the literature [32], the peak of the DSC curve of $\mathrm{MgSO}_{4} \cdot 7 \mathrm{H}_{2} \mathrm{O}$ is located at about $85{ }^{\circ} \mathrm{C}$ with the normalized heat flow of approximately $-0.86 \mathrm{~W} \cdot \mathrm{g}^{-1}$. It can be found from Figure 3 that the first peak of the normalized heat flow of XM15 is almost the addition of $85 \%$ of the heat flow of zeolite $13 \mathrm{X}$ and $15 \%$ of that of $\mathrm{MgSO}_{4} \cdot 7 \mathrm{H}_{2} \mathrm{O}$, which means that the impregnated $\mathrm{MgSO}_{4}$ in the zeolite $13 \mathrm{X}$ pellets experiences hydration and dehydration, contrary to the results reported by Mahon et al. [28].

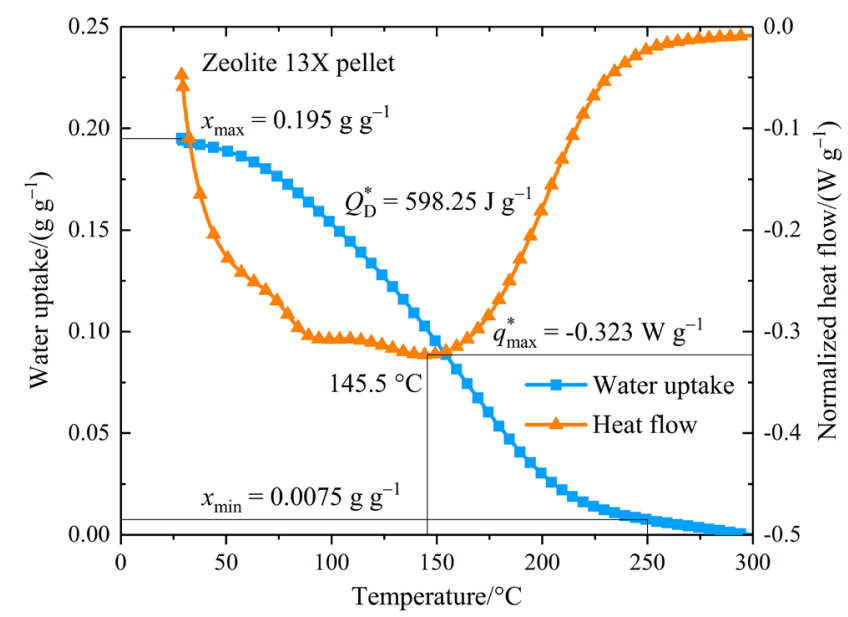

(a)

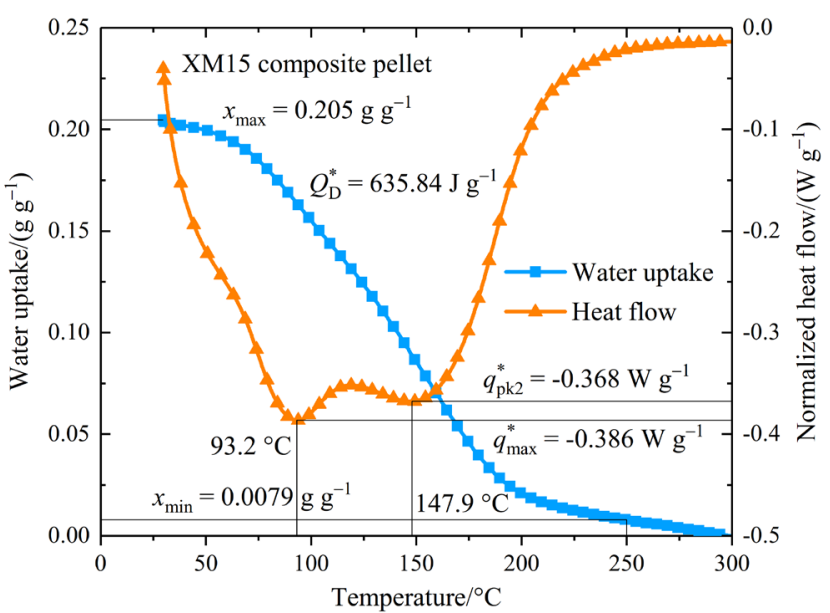

(b)

Figure 3. TGA/DSC STA results of (a) zeolite 13X and (b) XM15 pellets in the desorption processes.

\section{System description}

The TES device presented in this article adopted the novel design scenario with valve-less adsorber and separate reservoir. A lab-scale prototype was built in order to validate the new design scenario.

\subsection{Principle}

Basic sorption TES device mainly consists of an adsorber, a condenser/evaporator/reservoir, and a pipe with a valve connects the former two parts [4], as shown in Figure 4. In the charging phase, the adsorber is heated, and the adsorbate is desorbed from the adsorber and condensed in the condenser. The condenser also acts as the reservoir storing the liquid adsorbate. In the discharging phase, thermal energy is taken away from 
the adsorber, and the adsorbate in the evaporator evaporates and is adsorbed by the adsorbent in the adsorber. The valve between the adsorber and the condenser/evaporator/reservoir can separate the two vessels before the discharging phase starts to prevent self-discharging and realize long-term TES.
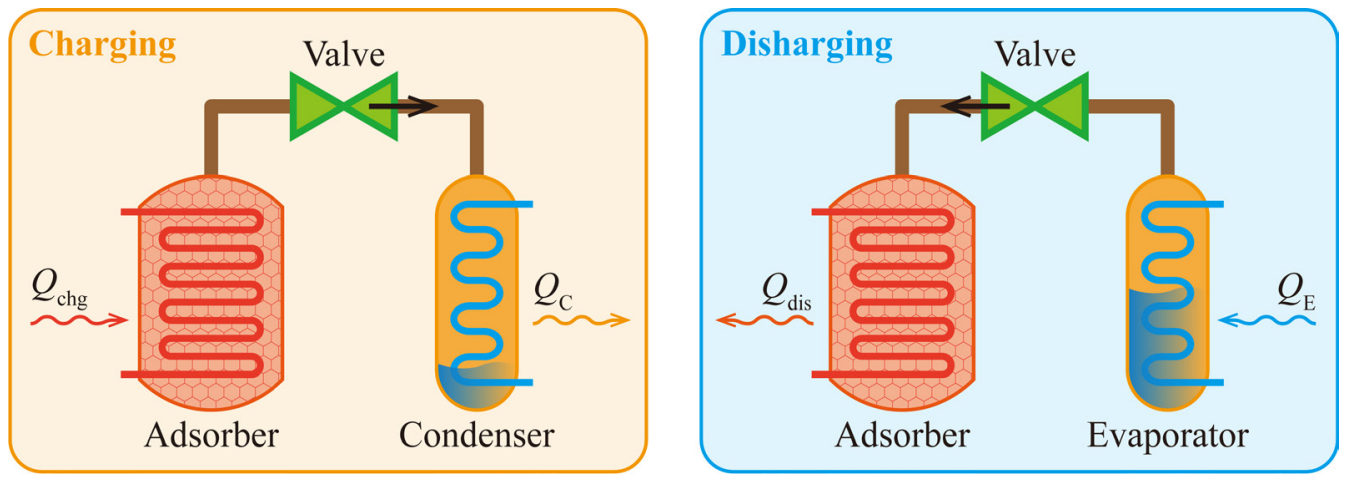

Figure 4. Schematic and working principle of basic sorption TES device

Many closed-system TES devices use the similar design scenario in Figure 4 [4], [5], [16], [18], [26], [30]; however, a large-diameter valve is necessary to reduce the vapor flow resistance and realize long-term TES. Such valves are usually expensive, bulky, and unwieldy, especially for vacuum and large-scale systems, which limits the household use of the TES device. To prevent using the large-diameter valve, the sorption TES device presented in this article adopted the valve-less adsorber design scenario where no valve is included between the adsorber and the condenser/evaporator, which decreases the cost, reduces the vapor flow resistance, and improves the system reliability. The main components of this device are an adsorber, a condenser/evaporator, and a reservoir, with pipes and valves connecting the condenser/evaporator and the reservoir, as shown in Figure 5.

The reservoir is linked to the condenser/evaporator through two pipes, one for pumping water from the reservoir to the condenser/evaporator (the pipe with valve 1), the other for draining water from the condenser/evaporator to the reservoir (the pipe with valve 2). Each pipe has a small-diameter vacuum valve to control the connectivity of the pipeline. No liquid pump is used in this device, and the pumping process is realized by the auxiliary electric heater attached to the reservoir. Since water can be stored in the reservoir and separated from the adsorber before discharging, this design scenario avoids the large-diameter vacuum valve between the adsorber and the condenser/evaporator for vapor flow. Furthermore, as the condenser/evaporator is located above the adsorber, the deliquescence of the salt will not cause loss of the effective mass of the sorbent. Hence, the energy storage capacity of the device will not decay even if deliquescence happens. 

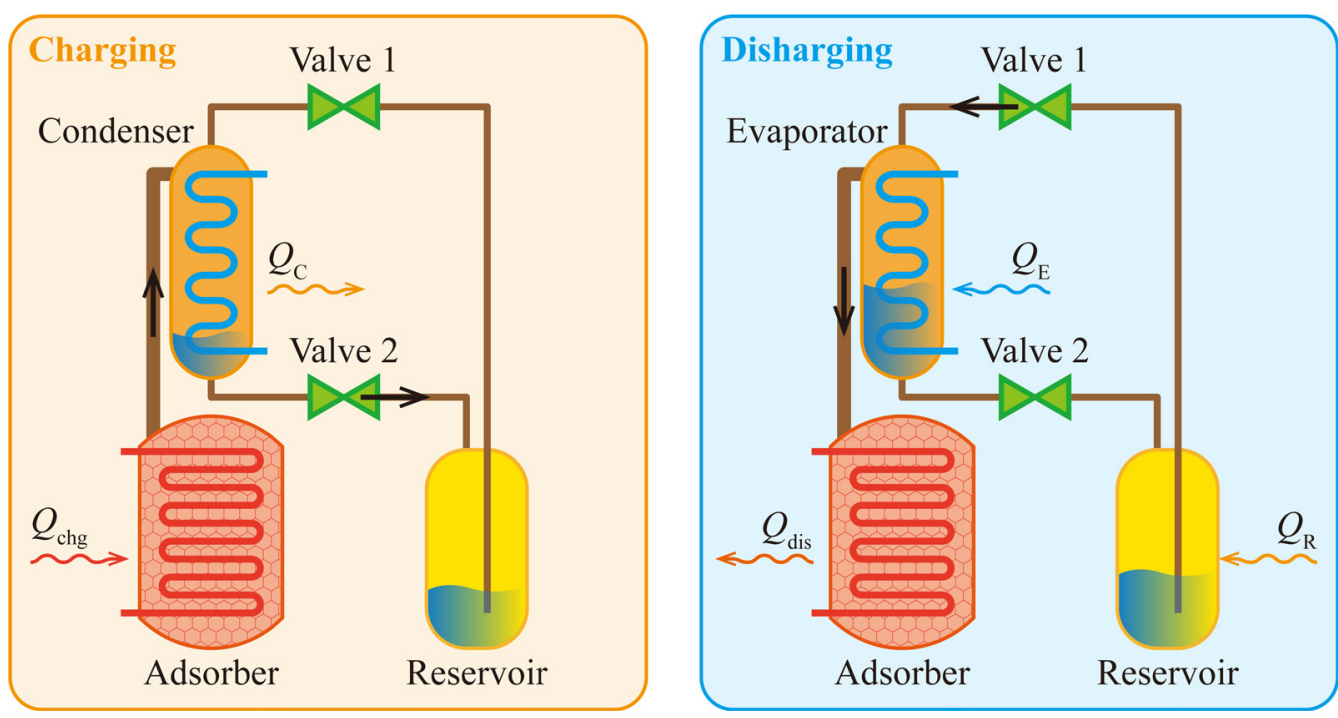

Figure 5. Schematic and working principle of sorption TES device with valve-less adsorber and separate reservoir.

Figure 6a shows the Clapeyron diagram of the basic adsorption cycle which can be used for both adsorption refrigeration and short-term adsorption TES. In Figure 6a, point 1 is the initial state of the adsorber, process $1-2-3$ is the charging (heating and desorption) phase, and process $3-4-1$ is the discharging (sensible heat and adsorption heat recovery) phase of the TES cycle.

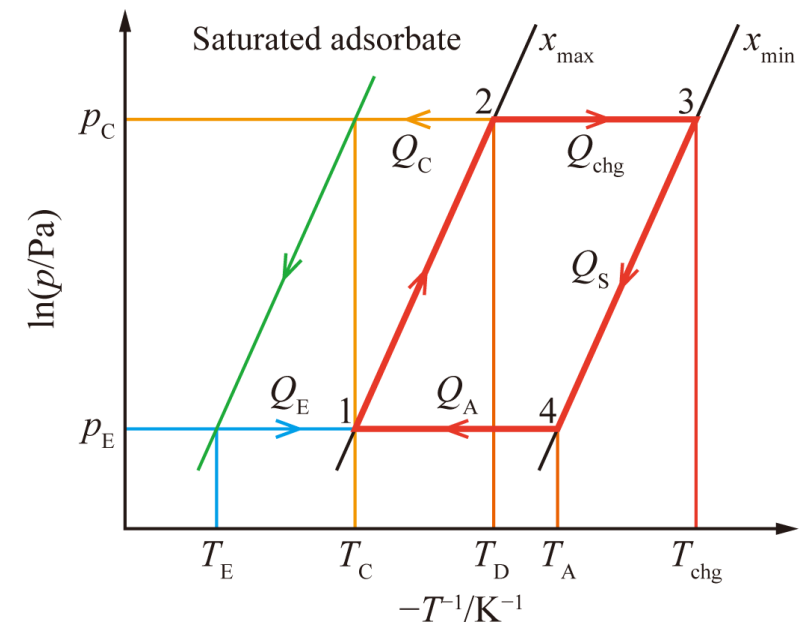

(a)

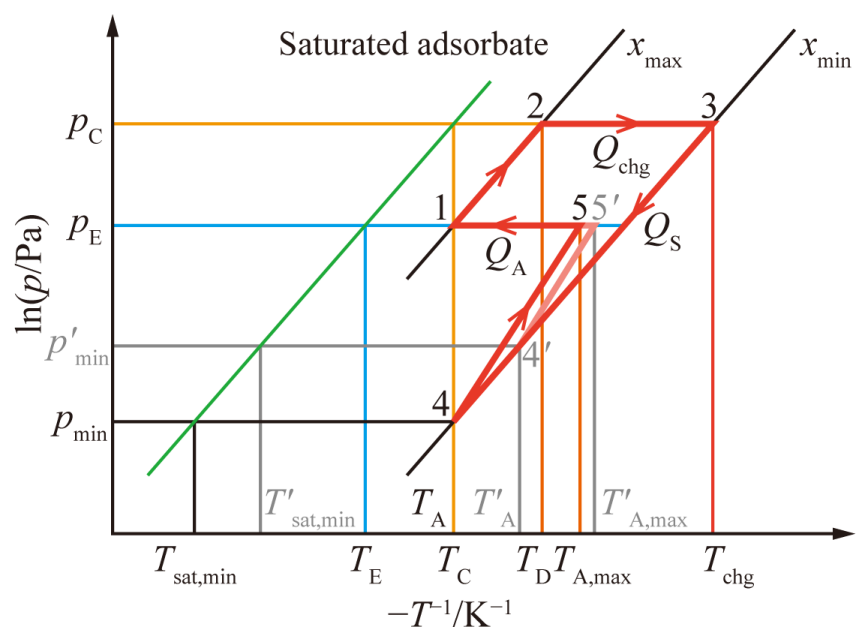

(b)

Figure 6. Clapeyron diagrams of (a) basic adsorption cycle and (b) applied adsorption TES cycle.

Figure $6 \mathrm{~b}$ illustrates the Clapeyron diagram of the applied TES cycle. In Figure 6b, cycle 1-2-3-4-5-1 is the long-term adsorption TES cycle. Process $1-2-3$ is the charging phase, process $3-4$ is the sensible heat recovery process, process $4-5$ is the adsorption process to reach the maximum adsorption temperature, and process $5-1$ is the adsorption heat recovery process. Cycle $1-2-3-4^{\prime}-5^{\prime}-1$ in Figure $6 \mathrm{~b}$ is the short-term 
adsorption TES cycle which is similar to the long-term cycle except that the temperature at the start of the adsorption process and the maximum adsorption temperature are different from those of the long-term cycle.

For the short-term cycle, the adsorption process starts before the completion of the sensible heat recovery process, which means that some of the sensible heat is recovered with adsorption heat simultaneously. For the long-term cycle, adsorption process starts after the end of the sensible heat recovery process. The adsorber is cooled to near ambient temperature to retrieve all the sensible heat, then the device can be left alone for some time, and the adsorption process is started subsequently for recovery of the adsorption heat. Generally, shortterm TES should have better performance, as it suffers from lower heat loss; however, it is of less significance in practice because there is only a short time difference between charging and discharging. The long-term cycle is more aligned with practical application.

\subsection{Prototype}

Figure 7 is the rendering schematic of the sorption TES device.

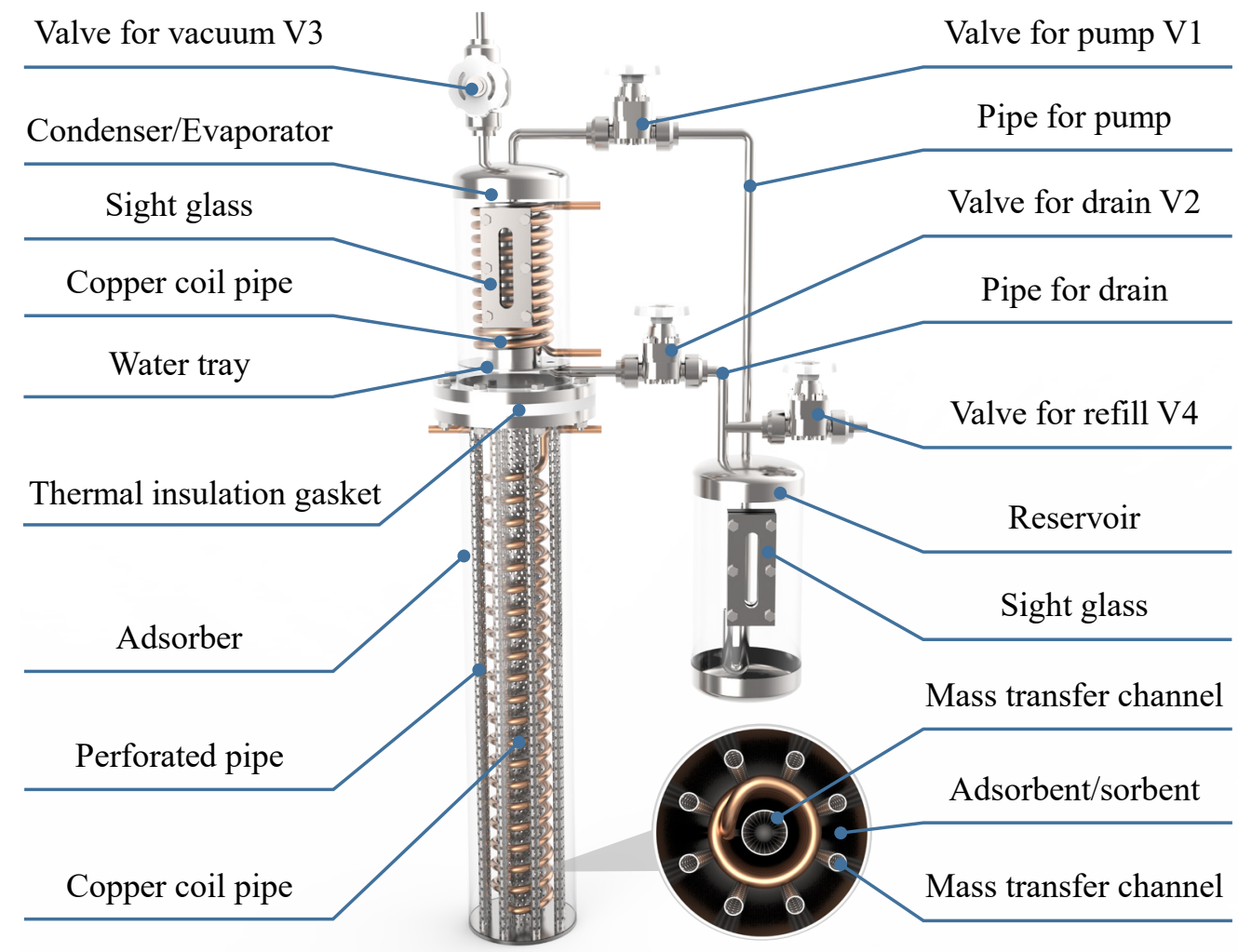

Figure 7. Rendering schematic of the sorption TES device.

As shown in Figure 7, the adsorber includes nine perforated pipes with wire mesh as the mass transfer 
channels. The copper coil pipe goes through the adsorbent to exchange heat. The adsorber is filled with $6.9 \mathrm{~kg}$ zeolite $13 \mathrm{X}$ and $345 \mathrm{~g}$ ENG-TSA. Besides, $2.5 \mathrm{~kg} \mathrm{MgSO}_{4} \cdot 7 \mathrm{H}_{2} \mathrm{O}$ (containing $1.22 \mathrm{~kg} \mathrm{MgSO}_{4}$ ) is added to produce the XM15/ENG-TSA composite sorbent. The adsorber is connected to the condenser/evaporator with a pair of flanges. A thermal insulation gasket is placed between the flanges to prevent the charging heat conducting from the adsorber to the condenser. A water tray is located in the condenser/evaporator. The copper coil pipe spirals between the shell and the water tray in the condenser/evaporator to exchange heat. Transparent sight glasses with scale are attached to the fronts of the condenser/evaporator and the reservoir. Pressure transducers are placed in the adsorber, the condenser/evaporator, and the reservoir, respectively. Pt100 temperature sensors are inserted into the adsorber, the reservoir, as well as the water flow inlets and outlets of the coil pipes. The charging heat is sourced from the electric heater attached to the adsorber with the rated power of $1.8 \mathrm{~kW}$. The auxilary electric heater is set to the reservoir with the power of $760 \mathrm{~W}$. The pressure in the reservoir can be elevated by a small amount of heat input with the auxiliary electric heater, and water can be pumped from the reservoir to the evaporator by the pressure difference between the reservoir and the evaporator. Moreover, the electric heater attached to the reservoir also manages to elevate the initial evaporating temperature, so the temperature lift also can be increased.

\section{Experimental}

The experimental system is mainly constituted by the TES prototype, a control box, a data measurement and acquisition system, a thermostatic bath, and water pipelines.

\subsection{Experimental procedure}

Figure 8 shows the photo and setup of the sorption TES experimental system. The device is evacuated in the vacuum condition through V3 before the experiment starts, and water is added through V4 into the reservoir. $\mathrm{V} 3$ and V4 are closed during the experiments.

In the charging phase, both V1 and V2 are closed, and the electric heater attached to the adsorber is switched on. The electric heater operates until the adsorbent temperature reaches $250{ }^{\circ} \mathrm{C}$. During this process, the flowing water in the coil pipe of the condenser/evaporator is kept on. The condenser/evaporator acts as the condenser. Water vapor is desorbed from the sorbent in the adsorber and condensed in the condenser. The flowing water in the coil pipe of the condenser is turnd off when no water vapor is observed to be condensed anymore. V2 is then opened to drain all the water from the condenser to the reservoir. Afterwards, V2 is closed.

The discharging phase includes the sensible heat recovery process and the adsorption heat recovery process. In the sensible heat recovery process, the flowing water in the coil pipe of the adsorber is kept on to 
recover the sensible heat. The flowing water in the coil pipe of the adsorber is turned off before the start of the adsorption process. The electric heater attached to the reservoir is turned on, and V1 is opened to pump water from the reservoir to the condenser/evaporator. The electric heater attached to the reservoir is switched off when the pressure difference between the reservoir and the condenser/evaporator is high enough (about 8$10 \mathrm{kPa}$ ), and V1 is closed after sufficient water is pumped. Afterwards, the flowing water in the coil pipe of the condenser/evaporator is turned on. The condenser/evaporator acts as the evaporator. When the sorbent in the adsorber reaches the maximum adsorption temperature, the flowing water in the coil pipe of the adsorber is turned on to recover the adsorption heat. The discharging phase lasts until no useful heat can be retrieved. After the discharging phase finishes, the flowing water in the coil pipes of the adsorber and the evaporator are turned off.

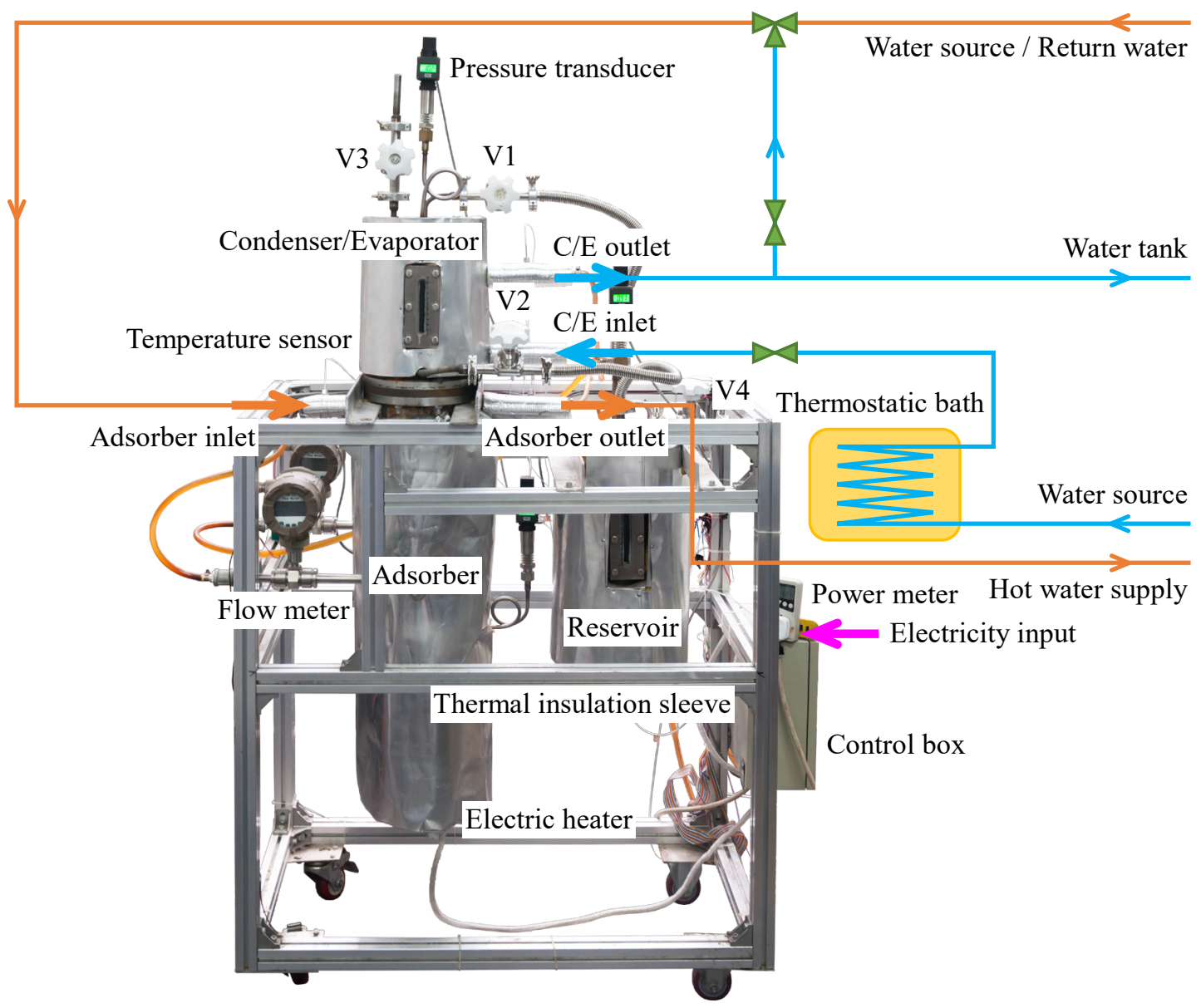

Figure 8. Photo and setup of the sorption TES experimental system.

The thermostatic bath is used to control the evaporating temperature of the TES device. When the evaporating temperature is higher than the room temperature, the outlet of the evaporator is connected to the inlet of the adsorber during the discharging phase. In this case, the discharging temperature will not be lower 
than the evaporating temperature.

\subsection{Data processing}

The heat discharged in the sensible heat or adsorption heat recovery process is calculated by

$$
Q_{\mathrm{S} / \mathrm{A}}=\dot{m}_{\mathrm{f}, \mathrm{S} / \mathrm{A}} c_{p, \mathrm{f}} \Delta \tau \sum_{j=1}^{\frac{\tau_{\mathrm{S} / \mathrm{A}}}{\Delta \tau}}\left(T_{\mathrm{f}, \mathrm{S} / \mathrm{A}, \mathrm{o}}-T_{\mathrm{f}, \mathrm{S} / \mathrm{A}, \mathrm{i}}\right)_{j}
$$

The condensation or evaporation heat is calculated by

$$
Q_{\mathrm{C} / \mathrm{E}}=\dot{m}_{\mathrm{f}, \mathrm{C} / \mathrm{E}} c_{p, \mathrm{f}} \Delta \tau \sum_{j=1}^{\frac{\tau_{\mathrm{CEE}}}{\Delta \tau}}\left|T_{\mathrm{f}, \mathrm{ClE}, \mathrm{o}}-T_{\mathrm{f}, \mathrm{Cl}, \mathrm{i}}\right|_{j}
$$

The energy efficiency of the TES device (including sensible and adsorption heat) is defined as

$$
\eta=\frac{Q_{\mathrm{dis}}}{W_{\mathrm{eh}}}=\frac{Q_{\mathrm{S}}+Q_{\mathrm{A}}}{W_{\mathrm{eh}}}
$$

If the condensation heat is regarded as useful heat output, the energy efficiency of the TES device will be

$$
\eta_{\mathrm{C}+}=\frac{Q_{\mathrm{S}}+Q_{\mathrm{A}}+Q_{\mathrm{C}}}{W_{\mathrm{eh}}}
$$

For seasonal TES, only the adsorption heat can be retrieved after a long time, so the seasonal energy efficiency of the TES device is

$$
\eta_{\mathrm{s}-}=\frac{Q_{\mathrm{A}}}{W_{\mathrm{eh}}}
$$

The specific energy storage capacity of the TES device is defined as the available discharging heat per unit mass of the sorbent (in $\mathrm{kJ} \cdot \mathrm{kg}^{-1}$ or $\mathrm{Wh} \cdot \mathrm{kg}^{-1}$ ), which is an important performance indicator revealing the TES capability of the sorbent and the system. The specific energy storage capacity is calculated by

$$
\mathrm{ESC}=\frac{Q_{\mathrm{dis}}}{m_{\mathrm{a}}}=\frac{Q_{\mathrm{S}}+Q_{\mathrm{A}}}{m_{\mathrm{a}}}
$$

The energy storage density of the TES device is another critical performance indicator defined as the available discharging heat per unit volume of the sorbent (in $\mathrm{MJ} \cdot \mathrm{m}^{-3}$ or $\mathrm{kWh} \cdot \mathrm{m}^{-3}$ ), which reflects how compact the TES system is with the particular sorbent. The energy storage density is calculated by

$$
\mathrm{ESD}=\frac{Q_{\text {dis }}}{V_{\mathrm{a}}}=\frac{Q_{\mathrm{S}}+Q_{\mathrm{A}}}{V_{\mathrm{a}}}
$$

The measurements by the instruments are generally assumed to have a continuous uniform (rectangular) distribution which has the standard deviation of the half interval length divided by $\sqrt{3}$ according to probability and statistics. Thus the systematic (type-B) uncertainty of instruments is calculated by 


$$
u_{\mathrm{B}}\left(z_{j}\right)=\frac{\delta z_{j, \max }}{\sqrt{3}}
$$

The uncertainty of the indirect measurement of the quantity $y$, which is the function of the directlymeasured quantities $z_{j}$, is calculated by

$$
u(y)=\sqrt{\sum_{j}\left[\left(\frac{\partial y}{\partial z_{j}}\right)^{2} u^{2}\left(z_{j}\right)\right]}
$$

The calculated uncertainties of the discharging heat and the energy efficiency of long-term TES with $\mathrm{XM} 15 / \mathrm{ENG}-\mathrm{TSA}$ are $\pm 4.2 \mathrm{~kJ}$ and \pm 0.005 , respectively.

\section{Results and discussion}

The TES prototype was tested under different conditions including different sorbents, adsorption temperatures, and evaporating temperatures.

\subsection{Prototype performance}

The adsorbent of zeolite 13X/ENG-TSA was first used in the prototype to validate the design scenario of the TES device. Afterwards, the newly developed composite sorbent of zeolite $13 \mathrm{X} / \mathrm{MgSO}_{4} / \mathrm{ENG}-\mathrm{TSA}$ was tested in the TES device.

\subsubsection{Test with zeolite $13 X / E N G-T S A$}

Figure 9 shows the evolutions of the temperatures and pressures in the long-term TES cycle with the zeolite $13 \mathrm{X} / \mathrm{ENG}-\mathrm{TSA}$ sorbent that is sufficiently regenerated in the vacuum condition.

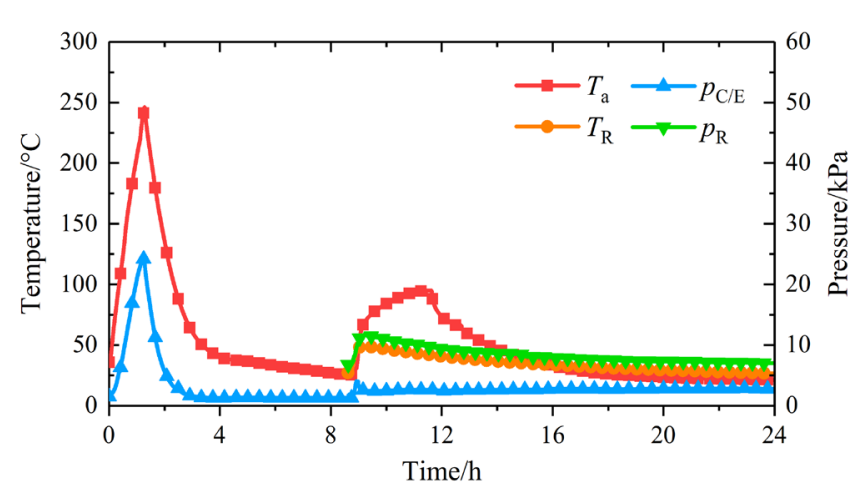

(a)

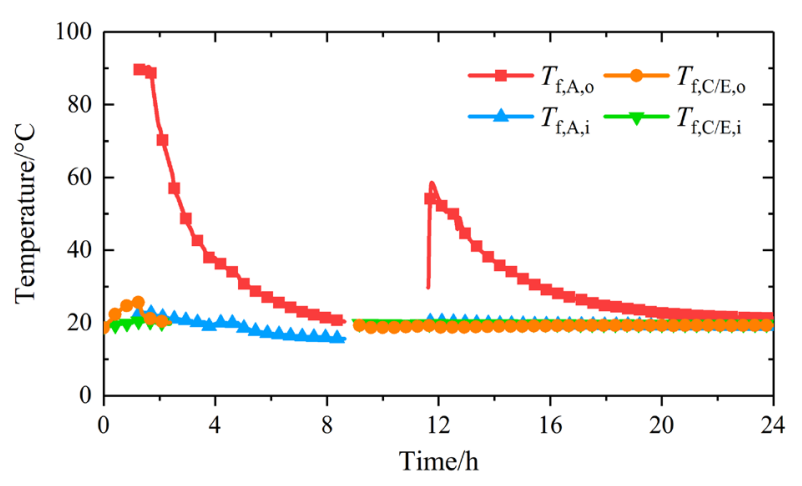

(b)

Figure 9. Evolutions of (a) temperatures and pressures in the TES device and (b) temperatures of the flowing water in the long-term cycle with zeolite 13X/ENG-TSA-water. 
The charging temperature is set to $250^{\circ} \mathrm{C}$ in consideration of the sufficient desorption and energy efficiency. Lower charging temperatures will result in the performance degradation after several cycles due to inadequate desorption, whereas higher charging temperatures will cause more heat loss and lead to the lower efficiency. The prototype with the zeolite 13X/ENG-TSA-water working pair realizes the long-term TES with the temperature lift of $69.6^{\circ} \mathrm{C}$. In the experiment, the electricity input is $2.31 \mathrm{kWh}(8323 \mathrm{~kJ})$, the condensation heat is $1416 \mathrm{~kJ}$, the sensible heat discharged is $2238 \mathrm{~kJ}$, and the adsorption heat discharged is $1827 \mathrm{~kJ}$. Accordingly, the energy efficiency is 0.49 , the energy efficiency taking condensation heat into account is as high as 0.66 , and the seasonal energy efficiency is 0.22 . The energy efficiencies are comparable to those reported in the literature [16], [18].

The efficiency loss of the TES device is mainly due to the heat loss of the electric heater as well as the heat dissipation to the environment. The energy efficiency of the device can be further improved through enhancing the thermal insulation, enlarging the scale of the prototype, or using the sorbent with a higher density. The condensing temperature is set to the room temperature in the experiments, so the availability of the condensation heat is very low. In order to better utilize the pressure and enthalpy of the desorbed water vapor in the charging phase, $\mathrm{V} 1$ can be occasionally opened in the condensing process. Thus the temperature and pressure in the reservoir will be increased, and the electricity input required to heat the reservoir and pump water to the evaporator can be reduced.

The specific energy storage capacity of the TES device with zeolite $13 \mathrm{X} / \mathrm{ENG}-\mathrm{TSA}$ is $155.9 \mathrm{Wh} \cdot \mathrm{kg}^{-1}$ $\left(561.2 \mathrm{~kJ} \cdot \mathrm{kg}^{-1}\right)$, and the energy storage density is $104.9 \mathrm{kWh} \cdot \mathrm{m}^{-3}\left(377.5 \mathrm{MJ} \cdot \mathrm{m}^{-3}\right)$. The performance is acceptable and proves the effectiveness of the design scenario with valve-less adsorber and separate reservoir.

\subsubsection{Test with zeolite $13 \mathrm{X} / \mathrm{MgSO} / \mathrm{A} / \mathrm{NG}$-TSA}

Figure 10 shows the evolutions of the sorbent temperatures during the adsorption heat recovery processes in the long-term TES cycles with the zeolite 13X/ENG-TSA and XM15/ENG-TSA sorbents which are sufficiently regenerated in the vacuum condition.

The temperature lift of the well-desorbed XM15/ENG-TSA during sorption process is $69.2{ }^{\circ} \mathrm{C}$, and the energy efficiency of long-term TES with XM15/ENG-TSA is 0.48 , which are similar to those of zeolite 13X/ENG-TSA. Figure 10 also displays that the impregnation of $\mathrm{MgSO}_{4}$ to zeolite $13 \mathrm{X}$ dramatically accelerates the temperature rising rate of the sorbent to approximately $300 \%$. Zeolite $13 \mathrm{X} / \mathrm{ENG}$-TSA requires approximately 3 hours to reach the maximum adsorption temperature, whereas XM15/ENG-TSA needs just about 1 hour. The results presented by Mahon et al. [28] also support this marked enhancement in the temperature rising rate of the $\mathrm{MgSO}_{4}$ impregnated zeolite $13 \mathrm{X}$. One explanation to this improvement in the temperature rising rate is that the drying process of the zeolite $13 \mathrm{X}$ impregnated with $\mathrm{MgSO}_{4}$ solution causes 
the recrystallization of $\mathrm{MgSO}_{4}$ and produces cracks which benefit the mass transfer in the pellets [28]. Nevertheless, according to the results in this article, enhanced mass transfer is not the only reason for the high temperature rising rate. In Figure 3, the DSC results demonstrate the sign of the dehydration of the $\mathrm{MgSO}_{4}$ hydrates, which implies that the hydration of $\mathrm{MgSO}_{4}$ also contributes to the rapid temperature increase.

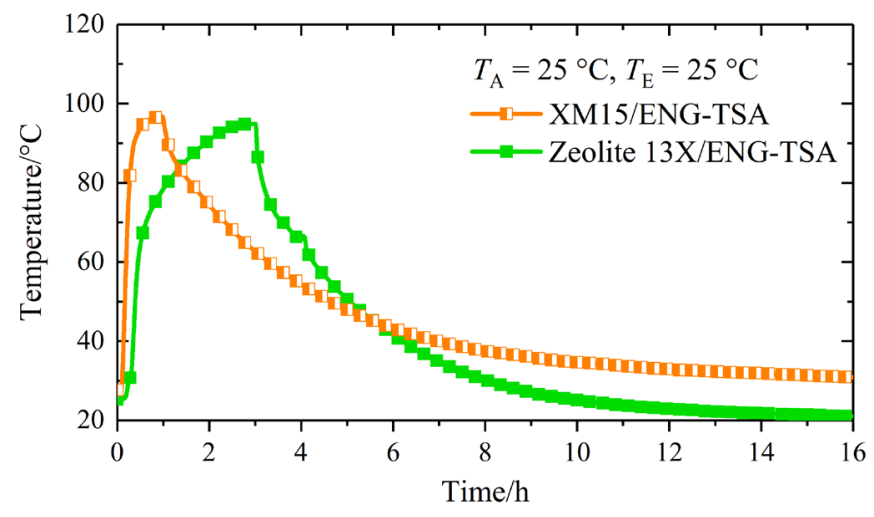

Figure 10. Evolutions of sorbent temperatures during the adsorption heat recovery processes in the long-term TES cycles with zeolite 13X/ENG-TSA-water and XM15/ENG-TSA-water.

Figure 11 shows the evolutions of the sorbent temperatures during the adsorption heat recovery processes with the XM15/ENG-TSA sorbent under different adsorption and evaporating temperatures.

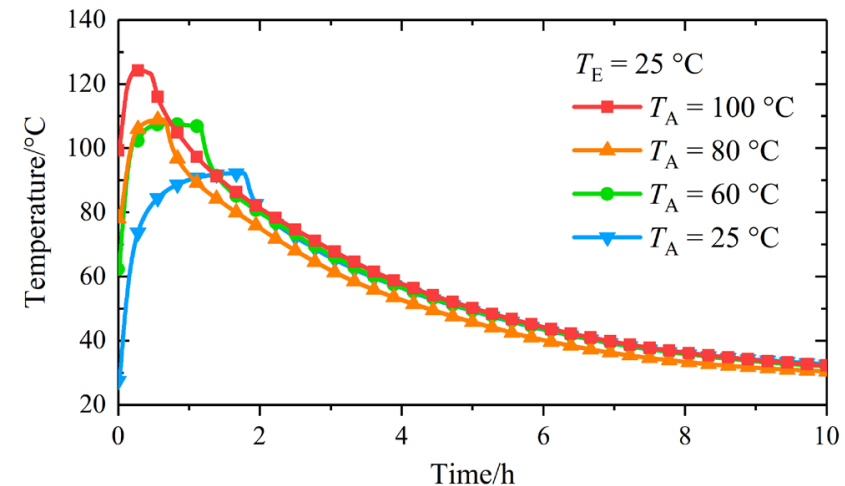

(a)

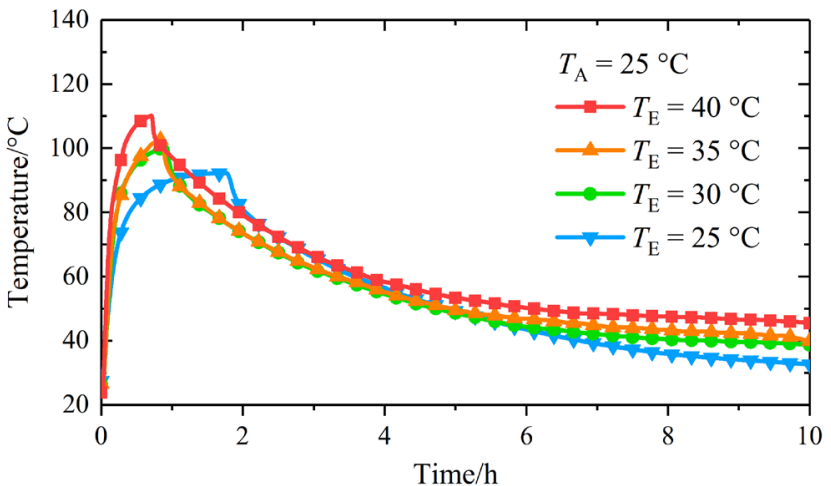

(b)

Figure 11. Evolutions of sorbent temperatures during the adsorption heat recovery processes with XM15/ENG-TSAwater under different (a) adsorption and (b) evaporating temperatures.

Figure 12 illustrates the distribution of the discharging heat in the sensible and adsorption heat recovery processes and the energy efficiencies with the XM15/ENG-TSA sorbent under different adsorption and evaporating temperatures. The performance of the device degrades a little and tends to be stable after several 
cycles due to the not thorough desorption and the slight loss of vacuum compared to the sufficiently regenerated sorbents in the vacuum condition.

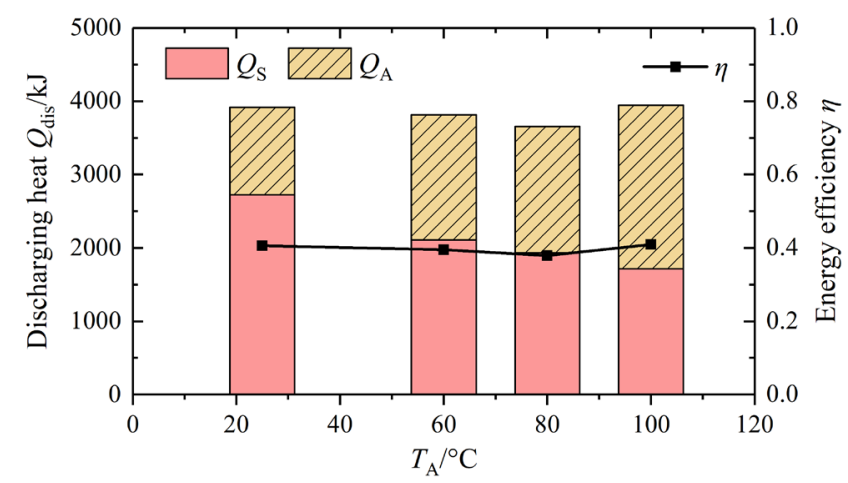

(a)

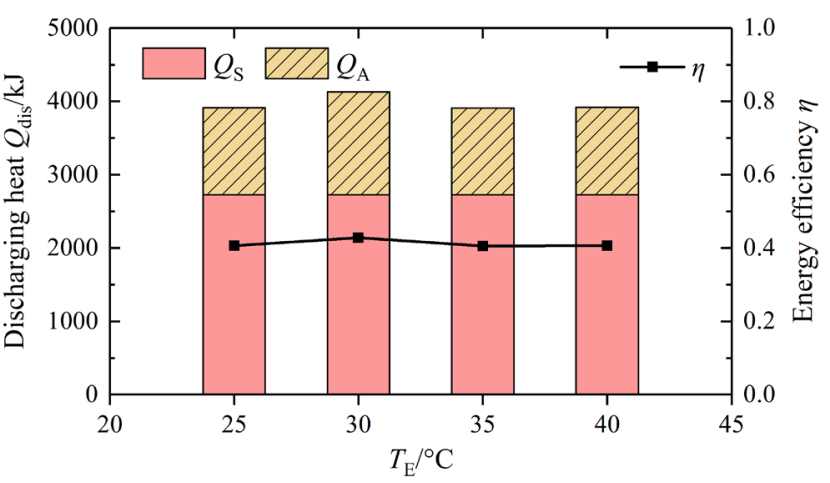

(b)

Figure 12. Distribution of discharging heat in the sensible and adsorption heat recovery processes and energy efficiencies with XM15/ENG-TSA-water under different (a) adsorption and (b) evaporating temperatures.

It can been seen from Figure 12 that the typical energy efficiency of the TES device is approximately 0.4 . Compared with the energy efficiency of 0.48 for the well-desorbed sorbent that is sufficiently regenerated in the vacuum, the performance degradation of the device is acceptable. The TES device can be restored to the best performance if the sorbent is regenerated at $250{ }^{\circ} \mathrm{C}$ thoroughly in the vacuum condition. As shown in Figure 12a, the energy efficiency at $100{ }^{\circ} \mathrm{C}$ adsorption temperature is higher compared with other conditions. The reason is that for the adsorption temperature of $100^{\circ} \mathrm{C}$, the sensible heat can be recovered most timely, and the adsorption heat can be recovered at the higher temperature and rate. Thus the discharging heat loss due to the heat dissipation to the environment at $100^{\circ} \mathrm{C}$ adsorption temperature is less than those under other conditions. Besides, as indicated in Figure $12 \mathrm{~b}$, the adsorption heat at $30^{\circ} \mathrm{C}$ evaporating temperature is higher compared with other conditions. The reason is that the increased partial pressure of water vapor promotes the hydration of $\mathrm{MgSO}_{4}$, whereas the higher sorbent temperature can hinder the hydration reaction [33]. The evaporating temperature of $30^{\circ} \mathrm{C}$ realizes a balance between the two kinetic influencing factors, similarly to the dehydration process [34].

Table 1 presents the temperature lifts of the TES device with the XM15/ENG-TSA sorbent at different adsorption and evaporating temperatures. At the same evaporating temperature, the maximum adsorption temperature rises with the increase of the adsorption temperature where the adsorption process starts, whereas the temperature lift decreases with the increasing adsorption temperature. When the TES device is used for hot water supply, it has the function of the sorption heat pump if the waste hot water is utilized to heat the 
evaporator and elevate the evaporating temperature.

Table 2 outlines the performance parameters of the TES device with the XM15/ENG-TSA sorbent. Compared with zeolite 13X/ENG-TSA, the energy efficiencies are similar because the principle and structure of the prototype do not change. The specific energy storage capacity for zeolite 13X/ENG-TSA is 155.9 Wh $\mathrm{kg}^{-1}\left(561.2 \mathrm{~kJ} \cdot \mathrm{kg}^{-1}\right)$, and the specific energy storage capacity for XM15/ENG-TSA is $153.0 \mathrm{Wh} \cdot \mathrm{kg}^{-1}$ $\left(550.8 \mathrm{~kJ} \cdot \mathrm{kg}^{-1}\right)$. Although the discharging heat output increases from $4066 \mathrm{~kJ}$ for zeolite $13 \mathrm{X} / \mathrm{ENG}-\mathrm{TSA}$ to $4663 \mathrm{~kJ}$ for XM15/ENG-TSA, the two energy storage capacities are similar due to the added total mass with the impregnation of $\mathrm{MgSO}_{4}$. The energy storage is improved from $104.9 \mathrm{kWh} \mathrm{m}{ }^{-3}\left(377.5 \mathrm{MJ} \cdot \mathrm{m}^{-3}\right)$ for zeolite 13X/ENG-TSA to $120.3 \mathrm{kWh} \cdot \mathrm{m}^{-3}\left(432.9 \mathrm{MJ} \cdot \mathrm{m}^{-3}\right)$ for XM15/ENG-TSA correspondingly.

Table 1. Temperature lifts of the TES device with XM15/ENG-TSA-water at different adsorption and evaporating temperatures

\begin{tabular}{|c|c|c|c|}
\hline Working condition & $T_{\mathrm{A}, \max } /$ Temperature lift $^{\mathrm{a}}$ & Working condition & $T_{\mathrm{A}, \max } /$ Temperature lift \\
\hline$T_{\mathrm{A}}=25^{\circ} \mathrm{C}, T_{\mathrm{E}}=25^{\circ} \mathrm{C}$ & $92.2^{\circ} \mathrm{C} / 64.8^{\circ} \mathrm{C}$ & $T_{\mathrm{A}}=25^{\circ} \mathrm{C}, T_{\mathrm{E}}=25^{\circ} \mathrm{C}^{\mathrm{b}}$ & $92.2^{\circ} \mathrm{C} / 64.8^{\circ} \mathrm{C}$ \\
\hline$T_{\mathrm{A}}=60^{\circ} \mathrm{C}, T_{\mathrm{E}}=25^{\circ} \mathrm{C}$ & $107.5^{\circ} \mathrm{C} / 45.2^{\circ} \mathrm{C}$ & $T_{\mathrm{A}}=25^{\circ} \mathrm{C}, T_{\mathrm{E}}=30^{\circ} \mathrm{C}$ & $100.3^{\circ} \mathrm{C} / 73.8^{\circ} \mathrm{C}$ \\
\hline$T_{\mathrm{A}}=80^{\circ} \mathrm{C}, T_{\mathrm{E}}=25^{\circ} \mathrm{C}$ & $108.9^{\circ} \mathrm{C} / 30.6^{\circ} \mathrm{C}$ & $T_{\mathrm{A}}=25^{\circ} \mathrm{C}, T_{\mathrm{E}}=35^{\circ} \mathrm{C}$ & $102.7^{\circ} \mathrm{C} / 76.1^{\circ} \mathrm{C}$ \\
\hline$T_{\mathrm{A}}=100^{\circ} \mathrm{C}, T_{\mathrm{E}}=25^{\circ} \mathrm{C}$ & $124.3^{\circ} \mathrm{C} / 25.0^{\circ} \mathrm{C}$ & $T_{\mathrm{A}}=25^{\circ} \mathrm{C}, T_{\mathrm{E}}=40^{\circ} \mathrm{C}$ & $110.1^{\circ} \mathrm{C} / 86.3^{\circ} \mathrm{C}$ \\
\hline
\end{tabular}

a The actual adsorption temperatures slightly deviate from the set values, and the temperature lifts are calculated from the experimental data logged.

$\mathrm{b}$ The particular working condition is repeated once for convenient comparison of results with other working conditions.

Table 2. Performance parameters of the TES device with XM15/ENG-TSA-water working pair

\begin{tabular}{llll}
\hline Parameter & Value & Parameter & Value \\
\hline Total mass of sorbent & $8.465 \mathrm{~kg}$ & Density of sorbent & $786 \mathrm{~kg} \cdot \mathrm{m}^{-3}$ \\
Electricity input & $2.68 \mathrm{kWh}$ & Discharging heat output & $4663 \mathrm{~kJ}$ \\
Charging temperature & $250{ }^{\circ} \mathrm{C}$ & Energy efficiency & $0.38-0.48$ \\
Discharging temperature & $25-90^{\circ} \mathrm{C}$ & Seasonal energy efficiency & 0.20 \\
Long-term temperature lift & $64.8-86.3^{\circ} \mathrm{C}$ & Specific energy storage capacity & $153.0 \mathrm{Wh} \cdot \mathrm{kg}^{-1}$ \\
Maximum power output & $153-966 \mathrm{~W}^{\mathrm{a}}$ & Energy storage density & $120.3 \mathrm{kWh} \cdot \mathrm{m}^{-3}$ \\
\hline
\end{tabular}

${ }^{a}$ The maximum power output depends on the type of the heat recovery process (sensible heat or adsorption heat) and the choice of the flow rate. 
The selected working boundary conditions for the TES device almost covers the reaction conditions of anhydrous magnesium sulfate and heptahydrate [27], [32], [33]. The theoretical specific energy storage capacity of $\mathrm{MgSO}_{4}$ is $3377.0 \mathrm{~kJ} \cdot \mathrm{kg}^{-1}$ calculated from the reaction enthalpy [35]. It can be seen from the experimental results that the impregnated $\mathrm{MgSO}_{4}$ significantly improves the temperature rising rate but fails to display its full theoretical specific energy storage capacity. In Figure 13, the energy storage densities of $\mathrm{MgSO}_{4} \cdot 7 \mathrm{H}_{2} \mathrm{O}$, zeolite $13 \mathrm{X} / \mathrm{ENG}-\mathrm{TSA}, \mathrm{XM15} / \mathrm{ENG}-\mathrm{TSA}$, and some typical TES media are illustrated for comparison [15], [20], [36].

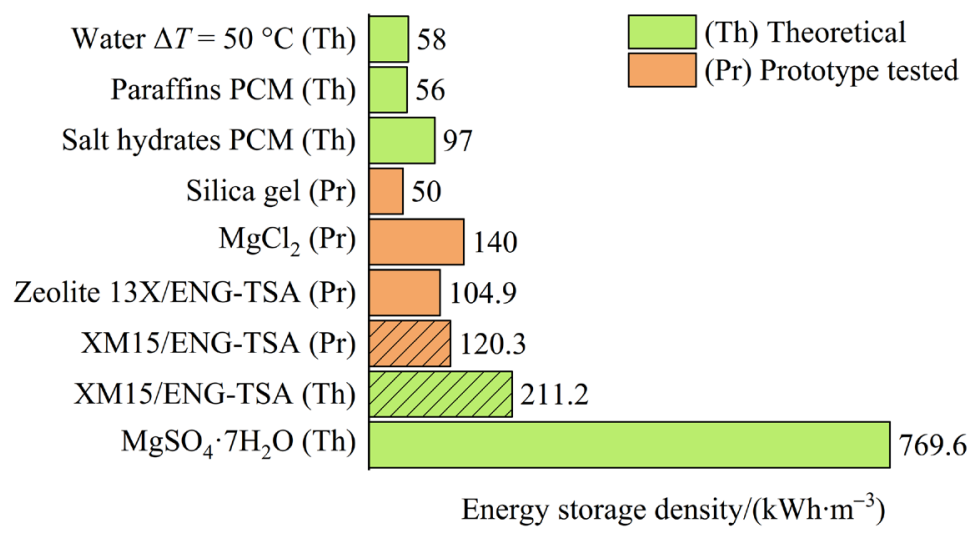

Figure 13. Comparison of energy storage densities of $\mathrm{MgSO}_{4} \cdot 7 \mathrm{H}_{2} \mathrm{O}$, zeolite $13 \mathrm{X} / \mathrm{ENG}-\mathrm{TSA}$, XM15/ENG-TSA, and some typical TES media

\subsection{Effect of magnesium sulfate}

The initial material characterization experiment of $\mathrm{MgSO}_{4}$ shows that the material thickness is an essential factor in kinetics, and thicker layers result in slower uptake of water [26]. The reason is that the salt crystals may clump together and form a hardly impermeable layer that prevents further water uptake of the material. Dispersing the salt in a host matrix is a solution to this self-hindrance issue [21], [37], [38]. Nevertheless, the host matrix of zeolite $13 \mathrm{X}$ cannot reach the full theoretical TES capability of the impregnated $\mathrm{MgSO}_{4}$. Some researchers provided explanations concerning this TES performance reduction of the $\mathrm{MgSO}_{4}$ impregnated zeolite compared to the theoretical value. The viewpoints can mainly be summarized as that the impregnated $\mathrm{MgSO}_{4}$ molecules block or break the structure of some pores in the host matrix [27], [28], [31]. The molar volumes of $\mathrm{MgSO}_{4}$ and $\mathrm{CaCl}_{2}$ are $45.25 \mathrm{~cm}^{3} \cdot \mathrm{mol}^{-1}$ and $51.62 \mathrm{~cm}^{3} \cdot \mathrm{mol}^{-1}$, respectively, which reveals that the space occupied by one $\mathrm{MgSO}_{4}$ molecule in average is close to that of $\mathrm{CaCl}_{2}$. Nonetheless, it seems that $\mathrm{CaCl}_{2}$ does not suffer from the marked decrease of the water uptake compared to the theoretical value when impregnated in zeolite $13 \mathrm{X}$ for sorption cooling [39]. Consequently, the pore blocking effect may not be the 
only contributing factor.

Figure 14 shows the relative humidity-temperature phase diagram of $\mathrm{MgSO}_{4}-\mathrm{H}_{2} \mathrm{O}$ system modified from the literature [38]. During the sorption process, the partial pressure of water vapor is close to the saturation pressure at the evaporating temperature. As plotted in Figure 14 , at $25^{\circ} \mathrm{C}$ evaporating temperature, the stable substance above $35{ }^{\circ} \mathrm{C}$ is magnesium sulfate monohydrate, which means that hexahydrate or heptahydrate cannot be formed if the sorbent temperature rises to above $35^{\circ} \mathrm{C}$. As a result, the self-hindrance effect of the hydration of $\mathrm{MgSO}_{4}$ also comes from the level of reaction kinetics under certain conditions [33]. During the sorption process, the initial raid reaction between $\mathrm{MgSO}_{4}$ and water vapor improves the overall water uptake kinetics performance of the XM15 sorbent compared with pure zeolite 13X. When the aqueous solution phase is formed under high relative humidity, the existence of zeolite 13X helps adsorb the excess water and promotes the crystallization of $\mathrm{MgSO}_{4}$ hydrates which is an exothermic reaction. This direction of hydration of $\mathrm{MgSO}_{4}$ through crystallization from supersaturated solution is kinetically preferred [33]. However, the high and rapid temperature lift of the sorbent prevents the persistent hydration of $\mathrm{MgSO}_{4}$ and can even cause partial decomposition of the hydrates formed in the adsorption heat recovery process.

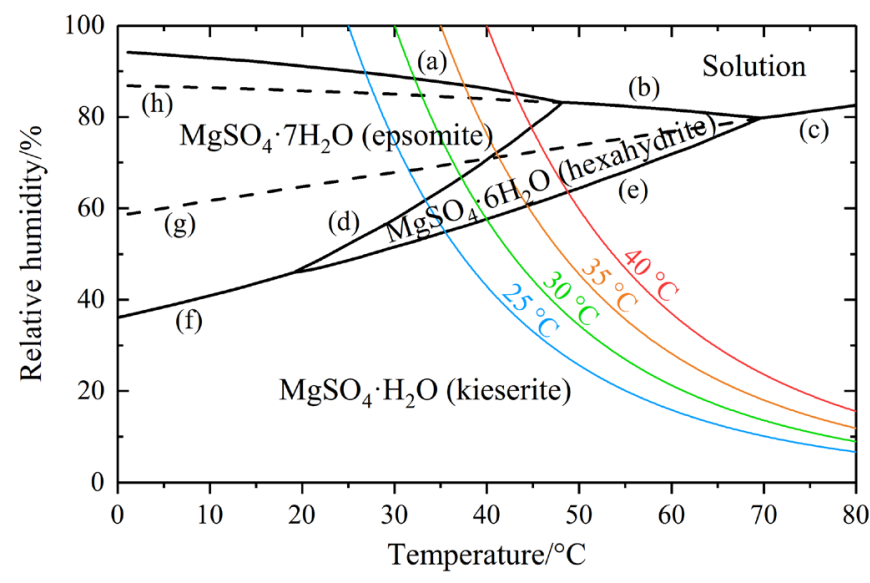

Figure 14. Relative humidity-temperature phase diagram of $\mathrm{MgSO}_{4}-\mathrm{H}_{2} \mathrm{O}$ system with deliquescence-crystallization equilibria of (a) $\mathrm{MgSO}_{4} \cdot 7 \mathrm{H}_{2} \mathrm{O}$ (epsomite), (b) $\mathrm{MgSO}_{4} \cdot 6 \mathrm{H}_{2} \mathrm{O}$ (hexahydrite), and (c) $\mathrm{MgSO}_{4} \cdot \mathrm{H}_{2} \mathrm{O}$ (kieserite), hydrationdehydration equilibria of (d) hexahydrite-epsomite, (e) kieserite-hexahydrite, and (f) kieserite-epsomite, deliquescence curves of $(\mathrm{g}) \mathrm{MgSO}_{4} \cdot \mathrm{H}_{2} \mathrm{O}$ and (h) $\mathrm{MgSO}_{4} \cdot 6 \mathrm{H}_{2} \mathrm{O}$, and saturated temperature curves of $25^{\circ} \mathrm{C}, 30{ }^{\circ} \mathrm{C}, 35^{\circ} \mathrm{C}$, and $40{ }^{\circ} \mathrm{C}$.

In consequence, $\mathrm{MgSO}_{4}$ can be impregnated to the TES media with lower temperature lifts compared with zeolite $13 \mathrm{X}$, which is a solution to the self-hindrance effect of the hydration of $\mathrm{MgSO}_{4}$ at high discharging temperatures. Besides, among the optional composite sorbents for TES systems with high discharging temperature, $\mathrm{CaCl}_{2}$ impregnated zeolite $13 \mathrm{X}$ is another promising TES medium. 
It can be seen that in the later period of the sorption process, the reaction rate of XM15 sorbent with water is not fast enough to provide temperature lift and useful heat output. In this circumstance, further water uptake should be restrained to reduce the desorption heat requirement that is unhelpful to improve the overall performance of the TES device. It is noticed that the full theoretical specific energy storage capacity is generally unavailable for practical application for reasons of heat and mass transfer in the prototype, reaction kinetics, as well as the discordance between the attainable discharging temperature/heat of the TES medium and the requirement of the demand side. Nevertheless, the performance indicators of energy storage density and specific energy storage capacity for TES systems can just reveal the attainable discharging heat at the preferred discharging temperature of the TES medium. Sometimes the discharging temperature that the TES medium favors does not coincide with the discharging temperature required by the demand side. As a result, it is essential to accompany data on discharging temperature and temperature lift with specific energy storage capacity and energy storage density. Alternatively, new performance indicators involving exergy [40] and entransy [41] can be defined to assess TES systems, as they contain information about the grade of energy or irreversibility in addition to the amount of energy.

\section{Conclusions}

This article presents the novel sorption thermal energy storage device with valve-less adsorber and separate reservoir for domestic heating. The outcomes of this study make the household use of the TES device more achievable. The following conclusions can be drawn from this study:

(1) The new design scenario with valve-less adsorber and separate reservoir eliminates the large-diameter vacuum valve for vapor flow in the previous studies, which decreases the cost, reduces the vapor flow resistance, and improves the system reliability. The design scenario is validated by the experiments with zeolite 13X/ENG-TSA and XM15/ENG-TSA sorbents and achieves the energy efficiency of $0.38-0.49$ ( 0.66 if considering condensing heat, $0.20-0.22$ for seasonal TES) with the charging temperature of $250^{\circ} \mathrm{C}$ and the discharging temperature of $25-90{ }^{\circ} \mathrm{C}$.

(2) The newly developed XM15/ENG-TSA composite sorbent accelerates the temperature rising rate during the sorption process to approximately $300 \%$ compared with zeolite $13 \mathrm{X} / \mathrm{ENG}-\mathrm{TSA}$. The energy storage density is improved from $104.9 \mathrm{kWh} \cdot \mathrm{m}^{-3}\left(377.5 \mathrm{MJ} \cdot \mathrm{m}^{-3}\right)$ for zeolite $13 \mathrm{X} / \mathrm{ENG}-\mathrm{TSA}$ to $120.3 \mathrm{kWh} \cdot \mathrm{m}^{-3}\left(432.9 \mathrm{MJ} \cdot \mathrm{m}^{-3}\right)$ for XM15/ENG-TSA. The temperature lift of the TES device with $\mathrm{XM} 15 / \mathrm{ENG}-\mathrm{TSA}$ is as high as $64.8-86.3{ }^{\circ} \mathrm{C}$, which is almost the highest temperature lift reported in the open literature.

(3) The pore blocking effect of the impregnated $\mathrm{MgSO}_{4}$ and the self-hindrance of the hydration reaction 
result in the difference between the theoretical and actual energy storage capacities of XM15. The high and rapid temperature lift of the sorbent prevents the persistent hydration of $\mathrm{MgSO}_{4}$. The effect of the impregnated $\mathrm{MgSO}_{4}$ suggests that $\mathrm{MgSO}_{4}$ can be used for low-temperature TES to relieve the self-hindrance of the hydration reaction.

\section{Acknowledgements}

This research was supported by the Foundation for Innovative Research Groups of the National Natural Science Foundation of China (NSFC) (Grant No. 51521004) and the International Exchanges 2015 Cost share Programme of the Royal Society and NSFC (Grant No. 51611130200).

The first author gratefully acknowledges the financial support of the British Council and the China Scholarship Council (Grant No. 201603780099) during the visit to the United Kingdom.

\section{References}

[1] World Energy Outlook Special Report 2015: Energy and Climate Change - Executive Summary: International Energy Agency (IEA), 2015.

[2] Dincer I, Acar C. A review on clean energy solutions for better sustainability. International Journal of Energy Research. 2015;39(5):585-606.

[3] Panwar NL, Kaushik SC, Kothari S. Role of renewable energy sources in environmental protection: A review. Renewable and Sustainable Energy Reviews. 2011;15(3):1513-24.

[4] Yu N, Wang RZ, Wang LW. Sorption thermal storage for solar energy. Progress in Energy and Combustion Science. 2013;39(5):489-514.

[5] Yan T, Li TX, Wang RZ. 18 - Thermochemical heat storage for solar heating and cooling systems. Advances in Solar Heating and Cooling: Woodhead Publishing; 2016. p. 491-522.

[6] Lizana J, Chacartegui R, Barrios-Padura A, Valverde JM. Advances in thermal energy storage materials and their applications towards zero energy buildings: A critical review. Applied Energy. 2017;203:219-39.

[7] González-Roubaud E, Pérez-Osorio D, Prieto C. Review of commercial thermal energy storage in concentrated solar power plants: Steam vs. molten salts. Renewable and Sustainable Energy Reviews. 2017;80:133-48.

[8] Tatsidjodoung P, Le Pierrès N, Luo L. A review of potential materials for thermal energy storage in building applications. Renewable and Sustainable Energy Reviews. 2013;18:327-49.

[9] Transition to Sustainable Buildings: Strategies and Opportunities to 2050: International Energy Agency (IEA), 2013. 
[10] Estimates of heat use in the United Kingdom in 2012: Department of Energy \& Climate Change, The UK Government, 2013.

[11] Finck C, Li R, Kramer R, Zeiler W. Quantifying demand flexibility of power-to-heat and thermal energy storage in the control of building heating systems. Applied Energy. 2018.

[12] Arteconi A, Hewitt NJ, Polonara F. State of the art of thermal storage for demand-side management. Applied Energy. 2012;93:371-89.

[13] Lund PD, Lindgren J, Mikkola J, Salpakari J. Review of energy system flexibility measures to enable high levels of variable renewable electricity. Renewable and Sustainable Energy Reviews. 2015;45:785-807.

[14] Shigeishi RA, Langford CH, Hollebone BR. Solar energy storage using chemical potential changes associated with drying of zeolites. Solar Energy. 1979;23(6):489-95.

[15] MODESTORE - Deliverable D14: Final report on Austrian field test period (performance and evaluation): AEE - Institute for Sustainable Technologies, 2005.

[16] Dawoud B, Amer EH, Gross DM. Experimental investigation of an adsorptive thermal energy storage. International Journal of Energy Research. 2007;31(2):135-47.

[17] Tatsidjodoung P, Le Pierrès N, Heintz J, Lagre D, Luo L, Durier F. Experimental and numerical investigations of a zeolite 13X/water reactor for solar heat storage in buildings. Energy Conversion and Management. 2016;108:488-500.

[18] Schreiber H, Graf S, Lanzerath F, Bardow A. Adsorption thermal energy storage for cogeneration in industrial batch processes: Experiment, dynamic modeling and system analysis. Applied Thermal Engineering. 2015;89:485-93.

[19] Weber R, Dorer V. Long-term heat storage with NaOH. Vacuum. 2008;82(7):708-16.

[20] Zondag H, Kikkert B, Smeding S, Boer Rd, Bakker M. Prototype thermochemical heat storage with open reactor system. Applied Energy. 2013;109:360-5.

[21] Van Essen V, Bleijendaal L, Kikkert B, Zondag H, Bakker M, Bach P. Development of a compact heat storage system based on salt hydrates. Conference Development of a compact heat storage system based on salt hydrates.

[22] Hui L, Edem NTK, Nolwenn LP, Lingai L. Evaluation of a seasonal storage system of solar energy for house heating using different absorption couples. Energy Conversion and Management. 2011;52(6):2427-36. [23] van Essen VM, Cot Gores J, Bleijendaal LPJ, Zondag HA, Schuitema R, Bakker M, et al. Characterization of Salt Hydrates for Compact Seasonal Thermochemical Storage. 2009(48906):825-30.

[24] Courbon E, D'Ans P, Permyakova A, Skrylnyk O, Steunou N, Degrez M, et al. Further improvement of the synthesis of silica gel and $\mathrm{CaCl} 2$ composites: Enhancement of energy storage density and stability over 
cycles for solar heat storage coupled with space heating applications. Solar Energy. 2017;157:532-41.

[25] Zhu D, Wu H, Wang S. Experimental study on composite silica gel supported $\mathrm{CaCl} 2$ sorbent for low grade heat storage. International Journal of Thermal Sciences. 2006;45(8):804-13.

[26] Bales C, Gantenbein P, Jaenig D, Kerskes H, Summer K, van Essen M. Laboratory tests of chemical reactions and prototype sorption storage units. A Report of IEA Solar Heating and Cooling programme - Task 32 Advanced storage concepts for solar and low energy buildings: Report B4 of Subtask B. 2008.

[27] Hongois S, Kuznik F, Stevens P, Roux J-J. Development and characterisation of a new MgSO4-zeolite composite for long-term thermal energy storage. Solar Energy Materials and Solar Cells. 2011;95(7):1831-7. [28] Mahon D, Claudio G, Eames PC. An experimental investigation to assess the potential of using MgSO4 impregnation and $\mathrm{Mg} 2+$ ion exchange to enhance the performance of 13X molecular sieves for interseasonal domestic thermochemical energy storage. Energy Conversion and Management. 2017;150:870-7.

[29] Wang LW, Metcalf SJ, Critoph RE, Thorpe R, Tamainot-Telto Z. Development of thermal conductive consolidated activated carbon for adsorption refrigeration. Carbon. 2012;50(3):977-86.

[30] Zhao YJ, Wang RZ, Zhang YN, Yu N. Development of SrBr2 composite sorbents for a sorption thermal energy storage system to store low-temperature heat. Energy. 2016;115(Part 1):129-39.

[31] Whiting G, Grondin D, Bennici S, Auroux A. Heats of water sorption studies on zeolite-MgSO4 composites as potential thermochemical heat storage materials. Solar Energy Materials and Solar Cells. 2013;112:112-9.

[32] Essen Vv, Zondag H, Schuitema R, Helden Wv, Rindt C. Materials for thermochemical storage; characterization of magnesium sulfate. Presented at: Eurosun. 2008;7:10.

[33] Steiger M, Linnow K, Juling H, Gülker G, Jarad AE, Brüggerhoff S, et al. Hydration of MgSO4·H2O and Generation of Stress in Porous Materials. Crystal Growth \& Design. 2008;8(1):336-43.

[34] Ferchaud CJ, Scherpenborg RAA, Zondag HA, de Boer R. Thermochemical Seasonal Solar Heat Storage in Salt Hydrates for Residential Applications - Influence of the Water Vapor Pressure on the Desorption Kinetics of MgSO4.7H2O. Energy Procedia. 2014;57:2436-40.

[35] Grevel K-D, Majzlan J, Benisek A, Dachs E, Steiger M, Fortes AD, et al. Experimentally Determined Standard Thermodynamic Properties of Synthetic MgSO4 $4 \mathrm{H} 2 \mathrm{O}$ (Starkeyite) and MgSO4·3H2O: A Revised Internally Consistent Thermodynamic Data Set for Magnesium Sulfate Hydrates. Astrobiology. 2012;12(11):1042-54.

[36] Cabeza LF, Castell A, Barreneche C, de Gracia A, Fernández AI. Materials used as PCM in thermal energy storage in buildings: A review. Renewable and Sustainable Energy Reviews. 2011;15(3):1675-95.

[37] Posern K, Linnow K, Niermann M, Kaps C, Steiger M. Thermochemical investigation of the water uptake 
behavior of MgSO4 hydrates in host materials with different pore size. Thermochimica Acta. 2015;611:1-9.

[38] Linnow K, Niermann M, Bonatz D, Posern K, Steiger M. Experimental Studies of the Mechanism and Kinetics of Hydration Reactions. Energy Procedia. 2014;48:394-404.

[39] Chan KC, Chao CYH, Sze-To GN, Hui KS. Performance predictions for a new zeolite $13 \mathrm{X} / \mathrm{CaCl}$ composite adsorbent for adsorption cooling systems. International Journal of Heat and Mass Transfer. 2012;55(11):3214-24.

[40] Xu SZ, Wang LW, Wang RZ. Thermodynamic analysis of single-stage and multi-stage adsorption refrigeration cycles with activated carbon-ammonia working pair. Energy Conversion and Management. 2016;117:31-42.

[41] Xu SZ, Wang RZ, Wang LW. Temperature-heat diagram analysis method for heat recovery physical adsorption refrigeration cycle - Taking multi-stage cycle as an example. International Journal of Refrigeration. 2017;74:254-68. 